$$
\begin{array}{r}
6-8-93 \\
E-7768
\end{array}
$$

NASA Technical Memorandum 106114

AIAA-93-2437

\title{
Performance Characteristics of a Variable-Area Vane Nozzle for Vectoring an ASTOVL Exhaust Jet up to $45^{\circ}$
}

Jack G. McArdle and Barbara S. Esker Lewis Research Center Cleveland, Ohio

Prepared for the 29th AIAA Joint Propulsion Conference cosponsored by the AIAA, SAE, ASME, and ASEE Monterey, California, June 28-30, 1993 


\title{
PERFORMANCE CHARACTERISTICS OF A VARIABLE-AREA VANE NOZZLE
}

\section{FOR VECTORING AN ASTOVL EXHAUST JET UP TO $45^{\circ}$}

\author{
Jack G. McArdle and Barbara S. Esker \\ National Aeronautics and Space Administration \\ Lewis Research Center \\ Cleveland, Ohio 44135
}

\section{Abstract}

Many conceptual designs for ASTOVL aircraft nced exhaust nozzles that can vector the jet to provide forces and moments for controlling the aircraft's movement or attitude in flight near the ground. A type of nozzle that can both vector the jet and vary the jet flow area is called herein a vane nozzle. Basically, the nozzle consists of parallel, spaced-apart flow passages formed by pairs of vanes (vanesets) that can be rotated on axes perpendicular to the flow. Two important features of this type of nozzle are the abilities to vector the jet rearward up to $45^{\circ}$ and to produce less harsh total pressure and velocity footprints during vertical landing than does an equivalent single jet.

A one-third-scale model of a generic vane nozzle was tested with unheated air at the NASA Lewis Research Center's Powered Lift Facility. The model had three parallel flow passages. Each passage was formed by a vaneset consisting of a long and a short vane. The longer vanes controlled the jet vector angle, and the shorter controlled the flow area. This report presents nozzle performance for three nominal flow areas (basic and $\pm \mathbf{2 1}$ percent of basic area), each at nominal jet vector angles from $-20^{\circ}$ (forward of vertical) to $+45^{\circ}$ (rearward of vertical). The tests were made with the nozzle mounted on a model tailpipe with a blind flange on the end to simulate a closed cruise nozzle, at tailpipeto-ambient pressure ratios from 1.8 to 4.0. Also included are jet wake data, single-vaneset vector performance for long/short and equal-length vane designs, and pumping capability. The pumping capability arises from the subambient pressure developed in the cavities between the vanesets, which could be used to aspirate flow from a source such as the engine compartment. Some of the performance characteristics are compared with characteristics of a single-jet nozzle previously reported.

\section{Introduction}

Several programs have been conducted at the NASA Lewis Research Center to advance the technology needed for practical advanced short-takeoff, verticallanding (ASTOVL) aircraft. These programs included studies and testing of hot-gas ingestion, integrated aircraft/propulsion controls, and ducting and nozzles for engine exhaust systems.

Many conceptual designs for ASTOVL aircraft need exhaust nozzles that can vector the jet to provide forces and moments for controlling the aircraft's movement or attitude in flight near the ground. An example is shown in Fig. 1. The ventral nozzle can be used for pitch trim or control in hover or for acceleration and lift augmentation during a short takeoff. The thrusters at the wing roots can be vectored for yaw trim or sideways travel or to provide roll moment by varying the thrust (i.e., the flow area) between the two sides.

At NASA Lewis the work with exhaust systems consisted of both experimental and analytical investigations using the PARC3D computational fluid dynamics code. $^{1-3}$ In addition, the detailed performance of a vectorable ventral nozzle, called the swivel nozzle, was reported previously. ${ }^{4}$ That nozzle is pictured in Fig. 2. It consists of a rectangular flow opening in a shell that can be pivoted on an axis parallel to the opening. The model tested could be vectored $\pm 23^{\circ}$, which is near the feasible limit with this type of design. Flow area was not varied but could have been varied easily by adjusting each half of the shell independently.

Another type of vectorable nozzle is called herein the vane nozzle. The generic model tested and reported in this paper is shown in Fig. 3. It is not a cascade nozzle but consists of three separate, spaced-apart pairs of vanes (vanesets) that form three parallel flow passages. (A nozzle of this type had been considered for use as a ventral lifting thruster in a program involving the E-7 full-scale model aircraft, ${ }^{5}$ but that part of the program was cancelled before testing was started.) Two important features of this nozzle are the abilities to vector flow rearward $45^{\circ}$ and to produce less harsh jet totalpressure and velocity footprints during vertical landing. The improvement in footprint is due to the spaced-apart jets, which dissipate energy more rapidly than an equivalent single jet. This characteristic was reported in $1964 .^{6}$

In the present model (again refer to Fig. 3) the front and rear vanes in each vaneset were adjusted separately. The longer (rear) vane controlled the jet vector 
angle, and the shorter (front) vane controlled the flow area. The long/short vaneset design was chosen because geometric layouts showed that the expected jet discharge angle was uniquely dependent on the longer vane angle for large changes in flow area. Conversely, vanesets having vanes of equal length might produce odd discharge vector angles near the zero vector (pure lift) position, resulting in difficult or impossible control problems. These geometric observations were tested experimentally, and the results, which were different than expected, are given in an appendix to this report.

The performance of other types of vane nozzles has been reported. ${ }^{7}$ Also, a vane nozzle with spaced-apart jets and movable vanes was recently patented (U.S. patent $6,076,512$ ).

This report presents the performance of the vane nozzle with unheated air for three nominal flow areas (basic and \pm 21 percent of basic area), each at nominal jet vector angles from $-20^{\circ}$ (forward of vertical) to $+45^{\circ}$ (rearward of vertical). Performance was measured at the NASA Lewis Powered Lift Facility with the vane nozzle mounted on a model tailpipe with a blind flange on the end to simulate a blocked cruise nozzle, at tailpipe-to-ambient pressure ratios $\mathrm{PR}_{5}$ up to 4.0. Also included are jet wake data, single-vaneset vector performance for long/short and equal-length vane designs, and pumping capability. The pumping capability arises from the subambient pressure developed in the cavities between the vanesets, which could be used to aspirate flow from a source such as the engine compartment. Some of the performance characteristics are compared with the swivel nozzle characteristics reported previously. ${ }^{4}$

\section{Apparatus}

\section{Model}

The generic vane nozzle tested is shown in Figs. 3 and 4. It consisted of three parallel, spaced-apart pairs of vanes (vanesets) that could be rotated on pivot axes perpendicular to the flow. The jet vector angle was controlled by varying the angular position of the longer (rear) vanes, and the flow area was controlled by varying the angular position of the shorter (front) vanes relative to the rear vanes. The rear vanes could be set at angles from $-20^{\circ}$ (forward of vertical) to $+45^{\circ}$ (rearward of vertical). The front vanes were positioned with a spacer block to give flow passage widths of 1.14 in. $\left(A_{\text {basic }}\right), 0.90$ in. ( $\left.0.79 A_{\text {basic }}\right)$, or 1.38 in. (1.21 $\left.A_{\text {basic }}\right)$. (See Appendix $A$ and Fig. 3 for nomenclature.) For every test the measured positions of the corresponding vanes in each vaneset were the same within $0.2^{\circ}$. The vanes were locked in place by clamps on the pivot shafts. The shafts were roughened with nickel-chromium flame spray to prevent slipping due to high hinge moments from pressure forces on the vane surfaces in some of the tests. Rubber seals were installed at the ends and at the pivot of each vane to prevent leakage. Holes were drilled in the sideplates to inject air into the spaces between vanesets for the pumping capability tests; these holes were plugged for the performance tests. The spaces between vanesets were divided by a structural wall on the axial centerline, giving a total of four injection cavities.

The vane nozzle was mounted on a model tailpipe as illustrated in Fig. 5. Two honeycomb flow straighteners and a boundary layer trip were located in the transition section to ensure uniform flow and a turbulent boundary layer into the model. The tailpipe had a blind flange at the end to simulate a blocked cruise nozzle.

Blocks to close off the front and rear flow passages for comparative performance tests of single vanesets having long/short or equal-length vanes are sketched in Fig. 6. The blocks were shaped to provide smooth inflow to the center vaneset position for those tests.

Facility

Powered Lift Facility.-The tests were performed at the NASA Lewis Powered Lift Facility (PLF), which is shown in Fig. 7. The PLF is a large outdoor test stand with a three-axis force-measuring system. With an 8-in.-diameter standard nozzle the force measurement was found to have $+0.5,-1.5$ percent inaccuracy in the axial (thrust) direction and $+0,-2.0$ percent inaccuracy in the vertical (normal force) direction at nozzle pressure ratios from 1.8 to 3.5 . The force measurement inaccuracies were mostly systematic in nature.

The facility supplied unheated air to the model from the laboratory central air system. Airflow rate was measured by an ASME long-radius nozzle in the supply line upstream of the model. With the 8-in.-diameter standard nozzle the measured flow rate was found to have \pm 0.5 percent inaccuracy at nozzle pressure ratios from 1.4 to 5 .

The inaccuracies of the facility measuring systems at the low flow and force levels encountered in the single-vaneset vector tests are not known. However, the data from those tests were consistent and repeatable; thus, the relative accuracy from test to test is believed to be very good. 
Auxiliary air supply.-The system used to provide airflow to the cavity openings for the pumping capability tests is shown in Fig. 8. All hose lengths were the same to promote equal flow to each cavity. The orifice and associated piping were calibrated in a flow laboratory and had \pm 1 percent measurement inaccuracy.

\section{Instrumentation and Data Processing}

\section{Instrumentation}

The model station and instrumentation diagrams are given in Fig. 9. Because flow total temperature was assumed to be constant throughout the model, only the facility thermocouples at the model inlet were used. Airflow was measured by an existing ASME nozzle in the facility piping upstream of the model.

The rake used to measure plume total pressure is shown in Fig. 10. It was mounted with the tips 17 in. from the exit plane for tests with both the vane nozzle and the swivel nozzle described previously. ${ }^{4}$

\section{Data Processing}

After airflow in the model had become steady, 20 "snapshot" scans of the transducer data were made at the rate of one scan per second. These data were converted to engineering units, averaged, and recorded by the laboratory central data system. The final computations were batch processed from the averaged data on a mainframe computer. The discrete pressures at stations 5 and 6 (see Fig. 9) were averaged to obtain single values of total pressure at those stations.

\section{Procedure}

\section{Vane Shaft Deflection Tests}

Before the model was mounted on the PLF, each vane was loaded with deadweights, putting up to 1500 in.-lb of torque on the pivot shaft to calibrate vane surface deflection due to hinge moment and to proof test the clamping mechanism.

\section{Performance Tests}

Each rear vane was set and clamped at the desired deflection angle, and then each front vane was set for the desired flow area by using a spacer block resting on the associated rear vane. All vane angles were measured before and after a test to be sure slipping had not occurred. Performance data were obtained at selected tailpipe-to-ambient pressure ratios $\mathrm{PR}_{5}$ from 1.8 to 4.0 or to the $\mathrm{PR}_{5}$ where the measured hinge moment was about 1350 in.-lb. Measured hinge moments were computed from the surface pressure taps on the center vaneset.

\section{Jet Wake Tests}

For the jet wake tests the vanesets were set as in the performance tests. Rake pressure data were obtained at $\mathrm{PR}_{5}=3$ for two axial rake positions, spaced 1 in. apart. The tests were repeated with the swivel nozzle described previously. ${ }^{4}$

\section{Single-Vaneset Vector Tests}

For the single-vaneset vector tests the front and rear flow passages were blocked as shown in Fig. 6, and the total pressure rake at station 6 was removed. The center vaneset was set as in the performance tests, and data were obtained at $\mathrm{PR}_{5}$ from 1.8 to 3.4 .

\section{Pumping Capability Tests}

Preliminary tests showed that the nozzle developed subambient pressure in the cavities between the spacedapart vanesets that could be used to aspirate air from an outside source such as the engine compartment. The quantity of air at atmospheric pressure that could be flowed through the largest round holes in the sideplates (see Fig. 4) was less than the nozzle was capable of pumping. In order to explore the capability, an auxiliary air supply was used to blow air into the cavities. Wall pressure taps in the cavities, protected from direct flow, were used to measure cavity pressure-the assumption being that maximum pumped flow occurred when the cavity pressure rose to equal ambient pressure.

For the pumping capability tests the vanesets were set as in the performance tests, and data were obtained at a pumped flow ratio of 1.5 percent for $\mathrm{PR}_{5}$ up to 3.5 (simulated engine compartment ventilation rate on the ground). For one of the tests all the available auxiliary air was injected into only one of the four cavities.

\section{Results and Discussion}

Typical and summarized results of the tests are presented in this section. The experimental data leading to these results, plus a list of symbols and definitions, are given in several appendices. The angle and force notation that is used throughout this report is shown in Fig. 3. 
Nozzle Performance Tests

Performance of the vane nozzle over its range of throat areas and vane angles is summarized in Fig. 11. These results are cross-plotted from the extensive experimental data in Appendix B.

Force parameters (Figs. 11(a) to (d)) are not given at the $45^{\circ}$ long-vane angle $\delta_{L V}$ because the jet impinged on the facility structure to nullify the load cell measurements. For all the other $\delta_{L V}$ settings tested, the general trends of the force parameters were similar for the three throat areas and for $\mathrm{PR}_{5}$ of 2 and 3 . Both the thrust force ratio $T / F$ and the normal force ratio $N / F$ changed smoothly as the long vanes were deflected. Trends in both the thrust and normal force ratios generally follow the "cosine law." The thrust force ratio was less at higher $\mathbf{P R}_{5}$ for several reasons (such as changing cavity pressure) but mostly because of aerodynamic limitations on vane internal surface pressures that are discussed under the forces and jet angle subsection in Appendix B. The effective jet deflection $\delta_{j}$ varied smoothly as the vanes were moved and was uniquely dependent on $\delta_{L V}$ The force coefficient was low, approximately 0.9 , relative to other jet propulsion nozzles because of internal expansion losses and/or subambient pressure that developed on some of the nonflow surfaces of the nozzle. Typical surface pressure distributions are shown in Appendix B.

Flow parameters (Figs. 11(e) to (g)) were dependent on the short-vane angle $\delta_{S V}$. For the tests $\delta_{S V}$ was adjusted to give the desired nominal geometric flow area after $\delta_{L V}$ was set. The same geometric flow area did not provide constant referred airflow over the full range of $\delta_{L V}$. However, a constant airflow rate could easily have been obtained by appropriately programming $\delta_{S V}$ relative to $\delta_{L V}$. The discharge coefficient was reasonably constant over most of the $\delta_{L V}$ range and is probably high enough to lead to moderate nozzle size and weight for many applications.

Hinge moments on the vane pivot axes are shown in Figs. 11(h) and (i). Moments were high on vanes that turned the flow. Both the long- and short-vane hinge moments were in directions that tended to open the throat. Throat area is sensitive to these geometric changes and likewise would be sensitive to vane warping from pressure or temperature.

Pressure in the cavities between the vanesets (Fig. 11(j)) was subambient for all conditions tested. This pressure could be used to aspirate air from an outside source, as discussed in the next section.

\section{Pumping Tests}

The capability of this nozzle to pump air into the subambient-pressure cavities between the spaced-apart vanesets was tested by blowing air into the cavities (see Apparatus section). The data obtained with this method are believed to be similar to those that would have been measured if the same mass of air were aspirated into the cavities through large holes from a static source, such as the surrounding atmosphere. The results shown in this section are summarized from the data in Appendix C.

Figure 12 shows the nozzle performance when equal fractions of the injected air $w_{\text {aux }}$ were blown into each of the four cavities. The $w_{\text {aux }}$ was metered at a constant 1.5 percent of the measured tailpipe flow. This ratio was chosen to be representative of engine compartment ventilation flow. Relative to the case of no cavity inflow at the same tailpipe pressure ratio, cavity pressure was reduced further, the force coefficient increased, and the effective jet angle and tailpipe flow rate did not change significantly.

Figure 13 shows the performance when all $w_{\text {aux }}$ was pumped into one of the four cavities. The injection air cavity pressure (Fig. 13(a)) decreased as the pumped flow ratio increased while the pressure in the other three cavities remained at the $w_{a u x}=0$ level. This result implies that each of the cavities could pump the same $w_{\text {aux }}$, giving a large total pumped flow ratio similar to that of an ejector. The other parts of Fig. 13 show performance parameters measured in the same test. As pumped flow ratio increased, the tailpipe airflow (Fig. 13(b)) decreased and the force coefficient (Fig. 13(d)) improved. No instrumentation was mounted to study these unusual results, but they were probably caused by interactions as the tailpipe and pumped flows mixed within the nozzle body.

\section{Jet Wake Test}

The total pressure on the lateral centerline of the nozzle plume was measured with the rake shown in Fig. 10. Data were obtained for both the vane nozzle (1.21 $A_{\text {basic }}=54.1$ in. $\left.^{2}\right)$ and the swivel nozzle ${ }^{4}$ $\left(A=62.1\right.$ in. $\left.^{2}\right)$ to demonstrate the effects of breaking the jet into long narrow pieces.

As shown in the sketches in Fig. 14, the rake tips were positioned in a measuring plane 17 in. from the nozzle exit. For the one-third-scale model this distance is equivalent to the typical ground height of an ASTOVL aircraft at touchdown. Wakes from the vane 
and swivel nozzles are compared in Fig. 14. The peak pitot pressure and indicated Mach number are both substantially less for the vane nozzle, although the plume is larger in size. The maximum total pressure in the wake corresponds to the maximum pressure on a ground plane the same distance from the nozzle exit, as described by Higgins and Wainwright. ${ }^{6}$ Thus, the pressure and velocity footprints of an ASTOVL aircraft would be less harsh with the vane nozzle than with a single-jet nozzle such as the swivel nozzle. Also, the acoustic noise (overall sound pressure level) produced by the wake from the vane nozzle would be expected to be less than that from an equivalent single-jet nozzle because the jet velocity decays faster.

\section{Single-Vaneset Vector Tests}

Tests of single vanesets consisting of long-plusshort or two long vanes were made by using the blocks sketched in Fig. 6 to close off the front and rear flow passages in the nozzle. The tests were done to determine the flow and vector characteristics of these different vaneset design concepts. Graphical layouts showed that the vector direction of the geometric throat was not uniquely related to vane position for vanes of equal length if throat area was kept constant. (The geometric throat is defined herein as the plane in the flow passage having minimum width.) Similar layouts showed that vanesets having a long and a short vane did not show the same characteristic; rather, a chosen throat vector direction could be obtained only with a singular setting of the longer vane. This feature was maintained over a wide range of throat areas by choosing a suitable length and angular setting for the short vane. The results given in this section are summarized from the data in Appendix D.

The performance of a vaneset having two of the long vanes from the vane nozzle is shown in Fig. 15. The effective jet angle varied smoothly over the vector range tested, even though the geometric throat direction changed in an S-shaped manner. The geometric throat positions are illustrated by sketches in the figure.

The behavior of a vaneset with a long rear vane and a short front vane, as used in the vane nozzle tests reported herein, is shown in Fig. 16. Both the geometric throat and the effective jet angle varied smoothly over the vector range tested. The jet always turned forward a few degrees more than directed by the geometric throat, which is attributed partially to expansion pressure on the long-vane surface downstream of the throat, as in a single-expansion ramp nozzle $\left(\mathrm{SERN}^{8}\right)$. Also, the jet turned about twice as much as with the equal-length vanes for the same vane angular travel (compare with Fig. 15). This characteristic would improve control response in an ASTOVL aircraft.

\section{Concluding Remarks}

Tests were done to demonstrate the performance of a one-third-scale vane nozzle mounted in the ventral position on a model tailpipe. The nozzle had three spaced-apart vanesets. Each vaneset consisted of a long rear vane and a short front vane. The jet vector angle was controlled by the longer vanes, and the flow area by the shorter vanes. Tests were performed with unheated air over a range of tailpipe-to-ambient pressure ratios $\mathrm{PR}_{5}$ up to 4 for three nozzle flow areas and nominal jet vector angles from $-20^{\circ}$ (forward of vertical) to $+45^{\circ}$ (rearward of vertical). However, reliable force data were not obtained at jet vector angles above $+30^{\circ}$. The most important results of these tests are the following:

1. The jet vector angle varied smoothly as the long-vane angle was changed. At $P_{5}=3$ the resultant force moved from $-16^{\circ}$ to $+29^{\circ}$ when the long vanes were moved from $-19^{\circ}$ to $+30^{\circ}$. It is believed that the jet continued to vector smoothly for deflection of the longer vane up to $+45^{\circ}$, but reliable force data were not obtained to verify that performance.

2. The nozzle thrust performance was poor relative to that of other convergent nozzles. The measured force coefficients were 0.90 or less over most of the tested ranges. Thrust losses mainly were caused by internal jet overexpansion and interactions, by subambient pressures on exposed surfaces, or by both.

3. The airflow rate was controlled by the position of the short vane relative to the long vane, which caused a throat to form in the opening between the vanes. Performance trends were generally similar for throat areas from 0.79 to 1.21 times the design throat area.

4. The nozzle flow capacity was acceptable. The measured discharge coefficients were greater than 0.92 over most of the tested ranges.

5. Subambient pressures were developed in the four compartment-like cavities between vanesets. Air from a separate source in amounts up to 1.5 percent of the tailpipe flow was injected equally into the cavities and caused no significant changes in nozzle performance. $U_{p}$ to 4.5 percent of the tailpipe flow was injected into only one of the cavities without increasing cavity pressure, implying that the nozzle could be made to pump large quantities of air, like an ejector. 
6. The peak footprint velocity and pressure were less than those caused by another nozzle, having a single jet, that could be suitable for similar applications (swivel nozzle). These results are attributed to the long, narrow, spaced-apart jets from the vane nozzle, which dissipate energy more rapidly than a single jet.

7. Tests of single vanesets having equal-length and long/short vanes showed significant differences in flowturning performance. The long/short design turned the jet through a larger vector angle than the equal-length design for the same angular travel of the vanes, and the discharge and force coefficients were as good or better than with equal-length vanes.

This type of nozzle has features that could make it attractive for flight application, such as wide ranges of throat area and jet vectoring and a less harsh totalpressure and velocity footprint than other useful vectoring nozzles. At the same time the vane nozzle is comparatively complex in configuration and has high hinge moments, long seal runs, and low thrust performance.

\section{Appendix A}

\section{Symbols and Definitions}

Also see Figs. 3(c) and (d).

\section{Symbols}

A geometric throat area, in. ${ }^{2}$

$\Delta A \quad$ change in geometric throat area, in. ${ }^{2}$; computed from geometry and hinge moments

$C_{D, 5}$ nozzle discharge coefficient; defined herein as the measured nozzle airflow divided by the ideal airflow that could pass through the same nozzle throat at the same tailpipe (station 5) total pressure and temperature

$C_{F, 5}$ nozzle force coefficient; defined herein as the measured combined thrust and normal forces divided by the ideal force that could be produced by the same (measured) airflow at the same tailpipe (station 5) total pressure and temperature

$F \quad$ nozzle resultant force, $\mathrm{lb}$

HM hinge moment produced by pressure forces on the vane surfaces, in.-lb

M Mach number

$N$ normal (vertical) force, lb

$P \quad$ pressure, psia

PR area-averaged total pressure divided by ambient pressure

$T$ thrust (horizontal) force, $l b$

w airflow, $\mathrm{lb} / \mathrm{sec}$

$\delta$ in flow or force context the ratio of total pressure to $14.696 \mathrm{psi}$

$\delta \quad$ in angle context the vane deflection or effective jet angle measured from the vertical direction

$\theta \quad$ ratio of total temperature to $518.7^{\circ} \mathrm{R}$

Subscripts

amb ambient

aux auxiliary (cavities' total inflow for pumping capability tests)

basic design value

cav cavity between vanesets

$j \quad$ jet

$L V \quad$ long vane

nom nominal value; measured during configuration setup with no airflow

$R V$ rear vane

SV short vane

$t$ total

th throat

v vaneset

0 performance characteristic with $w_{\text {aux }}=0$

$5 \quad$ station 5 (see Fig. 9)

6. station 6 (see Fig. 9)

Definitions

Normal force ratio

Pumped flow ratio

Referred airflow

Thrust force ratio normal force divided by nozzle resultant force, $N / F$

auxiliary airflow rate divided by tailpipe airflow rate, $w_{\text {aux }} / w_{5}$

tailpipe airflow referred to station 5 conditions, $(w \sqrt{\theta} / \delta)_{5}$, $\mathrm{lb} / \mathrm{sec}$

thrust force divided by nozzle resultant force, $T / F$ 


\section{Appendix B}

\section{Nozzle Performance Tests}

Tests of the vane nozzle assembled on the model tailpipe as illustrated in Fig. 5 were performed with unheated air over a range of tailpipe-to-ambient pressure ratios $P_{5}$ from 1.8 to 4 . The vanes were set to the desired positions with no airflow, as described in the Procedure section. The vane angles and throat area thus set are termed "nominal" values. With airflow, hinge moments were calculated from surface pressures measured on the center vaneset (Fig. 9(b)). Both the longand the short-vane hinge moments were in directions that tended to open the throat. Assuming that hinge moments were the same for the other two vanesets, the nominal vane angles and the throat area were corrected for changes due to the hinge moments for each data reading. The corrected values were used in computing all test results shown in Figs. B-1 to B-5. Performance parameters are plotted against $\mathrm{PR}_{5}$ for three nominal throat areas and nominal long-vane angles $\delta_{L V, n o m}$ from $-20^{\circ}$ to $+45^{\circ}$.

\section{Hinge Moments and Geometry Changes}

The measured hinge moments are shown in parts (a) and (b) of Figs. B-1 to B-5. Typically, hinge moments increased with $\mathrm{PR}_{5}$ and were highest on vanes that turned the airflow.

The hinge moments changed the vane angles as shown in parts (c) and (d) of the figures, and the throat area as shown in parts (e). Vane angle changes were as high as $2^{\circ}$ for the aerodynamic and structural designs used in this model. The increase in throat area was on the order of 10 percent over much of the tested ranges. Throat area changes due to vane twisting may not be as significant in flight hardware, depending on vane size and construction and pivot shaft stiffness.

\section{Airflow}

The measured tailpipe airflow referred to station 5 is shown in parts (f) of Figs. B-1 to B-5. For each nominal throat area the flow increase with $\mathrm{PR}_{5}$ was due mainly to vane deflections from hinge moments in the model tested. The discharge coefficient $C_{D, 5}$ given in parts $(\mathrm{g})$ of the figures is based on the corrected throat area. The coefficients are greater than 0.92 except for some of the configurations at low values of $\mathrm{PR}_{5}$ and for the $1.21 A_{\text {basic }}$ case at $\delta_{L V, \text { nom }}=45^{\circ}$ (Fig. B-5(g)). In the latter instance the flow rate may have been reduced by separation from the long vanes at the sharp flow turn near the vane pivots.

\section{Forces and Jet Angle}

The force coefficient, the normal force ratio, the thrust force ratio, and the effective jet angle are plotted in parts $(\mathrm{h}),(\mathrm{i}),(\mathrm{j})$, and $(\mathrm{k})$, respectively, of Figs. B-1 to $B-4$. The force coefficients were 0.9 or less over most of the tested ranges. This level is considered low for convergent nozzles. At $\delta_{L V \text {,nom }}=-20^{\circ}$ (Fig. B-1) the thrust and normal force ratios were relatively constant over the whole $\mathrm{PR}_{5}$ range for all throat areas. The probable reason is that the flow passages, illustrated in Fig. B-6(a), resembled and performed as simple convergent nozzles. In contrast the thrust force ratio decreased and the normal force ratio increased with $\mathrm{PR}_{5}$ at $\delta_{L V, \text { nom }}$ settings of $20^{\circ}$ and $30^{\circ}$ (e.g., Figs. B-3 and $B-4$, parts (i) and (j)). Similar results for SERN nozzles at nozzle pressure ratios between 2 and 3.5 were reported previously. ${ }^{8}$ This behavior is linked to the flowside vane surface pressures upstream of the throat. The pressures measured at two different choked values of $\mathrm{PR}_{5}$ are shown in Fig. B-7. As exemplified by these data, the flow was subsonic everywhere upstream of the throat, and the internal Mach number and surface pressure distributions were essentially the same at each $\mathrm{PR}_{5}$. This made the internal force acting on each vane approximately proportional to inlet total pressure. From momentum principles and disregarding other comparatively small forces (such as net forces from cavity pressure, expansion pressures on the long vanes downstream of the throat, and turning pressure forces on the vane supports upstream of the pivot axes), the measured thrust is the difference between the front and rear vane forces and thus tends to be proportional to nozzle total pressure or pressure ratio. In the choked $\mathrm{PR}_{5}$ range nozzle total force $F$ changed with pressure ratio at a greater rate than thrust, leading to a lower thrust force ratio $T / F$ as $\mathrm{PR}_{5}$ increased. Similar reasoning can explain the increasing normal force ratio $N / F$ as $\mathrm{PR}_{5}$ increased.

The effective jet angle is given in parts ( $k$ ) of Figs. B-1 to B-5.

The measured results imply that the vanes tested were too small (or too few in number) to turn the flow fully at higher values of $\mathrm{PR}_{5}$. For rearward vectoring $\left(+\delta_{L V}\right)$ performance might have been improved if the longer vanes were positioned in the front of each vaneset, but that configuration was not tested.

\section{Cavity Pressure}

Pressure levels measured in the cavities between the vanesets are given in parts (l) of Figs. B-1 to B-4 and part (h) of Fig. (B-5). The cavity pressure was always subambient, and the depression increased with higher nozzle flow rate and higher $\mathrm{PR}_{5}$. Although the pressure 
levels plotted were measured in the cavities, the levels are representative of pressures measured on the nonflow sides of the vanes.

\section{Vane Surface Pressures}

Pressures measured on the surfaces of the center vaneset in the $A_{\text {basic }}$ configurations are given in Figs. B-6 and B-7. The sketches are drawn to scale and illustrate vane positions for typical configurations that were tested. The inflow arrows are shown to suggest that the flow entering the nozzle probably had turned from the tailpipe more than the intended $90^{\circ}$, as reported in tests of ventral nozzles. ${ }^{1-4}$ Significant flow separation from the surface of the rear vane at the $+45^{\circ}$ angle (Fig. B-6(c)) is indicated by the low pressures measured near the pivot.

The data are presented for information with no further comment and may be useful in understanding the performance results and in designing other vane nozzles.

\section{Pressure Loss}

The total pressure lost by the flow in turning from the tailpipe (station 5) to the nozzle inlet (station 6) was measured by tubes located as sketched in Fig. 9(a). The averaged loss (Fig. B-8(a)) ranged from about 1 percent to 3.5 percent for all the configurations tested. The loss was dependent only on tailpipe flow rate, or Mach number, as expected. Figure B-8(b) shows that most of the loss occurred in the forward part of the ventral duct, as with other ventral nozzle configurations. ${ }^{1}$ At the highest referred flow rate the loss in the flow entering the front vaneset was over 12 percent, but the loss in the flow to the other two vanesets was about 0.5 percent.

The curves in Fig. B- 8 can be used to refer $C_{D, 5}$ to nozzle inlet pressure rather than to tailpipe pressure by using appropriate one-dimensional isentropic flow equations.

\section{Appendix C}

\section{Pumping Tests}

The capability of the vane nozzle to pump air from an outside source was studied by blowing air from an auxiliary supply $w_{\text {aux }}$ into the cavities between vanesets as described in the Procedure section. The inlets for the injected air were perpendicular to the thrust and normal force axes. Equal fractions of $w_{\text {aux }}$ were injected into each of the four cavities. Blowing was necessary because the largest round holes that could be drilled in the cavity outside wall were not large enough to provide the desired flow from atmospheric pressure. The data obtained by this technique are believed to satisfactorily describe the pumping characteristics of this type of nozzle.

Nozzle performance for a pumped flow ratio of 1.5 percent, nominal basic throat area, and several longvane angles is given in Figs. $\mathrm{C}-1$ to $\mathrm{C}-4$. The cavity pressure, parts (c) of the figures, was always less than the pressure with no injected flow, and the pressure was further reduced as $\mathrm{PR}_{5}$ increased. The injected air did not affect the effective jet angle significantly. In general, the force coefficient increased when air was injected, indicating that the ingested flow joined the vane flow and left the nozzle at high velocity. However, the force improvement was less, on a percentage basis, than the increase in nozzle exit airflow.

\section{Appendix D}

\section{Single-Vaneset Vector Tests}

The forces produced by single vanesets were studied with vanes mounted only at the center position on the nozzle and with the front and rear flow passages blocked as shown in Fig. 6. The vanes were set at selected angles as described in the Procedure section. In these tests the hinge moments were not measured, so that vane angle and throat area changes were calculated from data in Appendix B. Because of the low tailpipe airflow and the rounded entrance blocks, the measured total pressures at stations 5 and 6 were the same.

The performance of a vaneset consisting of two long vanes from the vane nozzle is shown in Fig. D-1 for nominal basic throat area and nominal rear vane angles, $\delta_{R V \text {,nom }}$ ranging from $-18.9^{\circ}$ to $+5.0^{\circ}$. For $\mathrm{PR}_{5}$ greater than about 2.5 the effective jet angle $\delta_{j}$ changed from $-4^{\circ}$ to $+4^{\circ}$, or a total of approximately $8^{\circ}$, over the tested range of vane angles. The discharge coefficient $C_{D, 5}$ was dependent on $\mathrm{PR}_{5}$ and also on the vane settings when $\delta_{R V}$ was less than $-9.5^{\circ}$. For $\mathrm{PR}_{5}$ greater than 2.5 the force coefficient $C_{F, 5}$ varied from 0.94 to 0.97 , and the discharge coefficient $C_{D, 5}$ varied from 0.86 to 0.97 for all the vane angles tested. The lower values of $C_{D, 5}$ were obtained with $\delta_{R V}$ set at large negative angles, which required the flow to turn from the tailpipe more than $90^{\circ}$.

The performance of a vaneset having a long rear vane and a short front vane, as used in the vane nozzle tests, is given in Fig. D-2 for nominal basic throat area and nominal rear vane angles from $-5.4^{\circ}$ to $+19.9^{\circ}$. These angle settings required about the same amount of 
vane travel as the equal-length vane configuration shown in Fig. D-1. The $\delta_{j}$ changed a total of $20^{\circ}$ and varied rather uniformly over the range of $\delta_{r v}$ tested. The discharge coefficient increased with $\mathrm{PR}_{5}$ but was not dependent on vane angle. Likewise, the force coefficient $C_{F, 5}$ was greater than 0.95 for all $\mathrm{PR}_{5}$ and vane settings tested.

The major performance difference between the two vaneset designs was in flow-turning capability. For about the same vane travel the vaneset with long/short vanes changed $\delta_{j}$ about $20^{\circ}$, as opposed to only about $8^{\circ}$ for the vaneset with equal-length vanes. The force coefficients were nearly the same at higher values of $\mathbf{P R}_{5}$ for both designs. The discharge coefficients were comparable except at large negative $\delta_{R V}$ settings with the equal-length vane configuration (see Fig. D-1(b)).

\section{$\underline{\text { References }}$}

1. McArdle, J.G., and Smith, C.F., "Experimental and Analytical Study of Close-Coupled Ventral Nozzles for ASTOVL Aircraft," NASA TM-103170, 1990.

2. Esker, B.S., and DeBonis, J.R., "Experimental and Analytical Studies of Flow Through a Ventral and Axial Exhaust Nozzle System for STOVL Aircraft," AIAA Paper 91-2135, June 1991.
3. McArdle, J.G., Esker, B.S., and Rhodes, J.R., "Internal Reversing Flow in a Tailpipe Offtake Configuration for SSTOVL Aircraft," AIAA Paper 92-3790, July 1992.

4. Esker, B.S., and McArdle, J.G., "Performance Characteristics of a One-Third-Scale Vectorable Ventral Nozzle for SSTOVL Aircraft," AIAA Paper 90-2271, July 1990.

5. Jenista, J.E., and Bodden, D.S., "Configuration E-7 Supersonic Fighter/Attack Technology Program," Journal of Engineering for Gas Turbines and Power, Vol. 112, Apr. 1990, pp. 212-216.

6. Higgins, C.C., and Wainwright, T.W., "Dynamic Pressure and Thrust Characteristics of Cold Jets Discharging From Several Exhaust Nozzles Designed for VTOL Downwash Suppression," NASA TN D-2263, 1964.

7. Meyer, B.E., Re, R.J., and Yetter, J.A., "Scale Model Results of Several STOVL Ventral Nozzle Concepts," AIAA Paper 91-2134, June 1991.

8. Berrier, B.L., and Leavitt, L.D., "Static Internal Performance of Single-Expansion Ramp Nozzles With Thrust Vectoring Capability up to $60^{\circ}$," NASA TP-2364, 1984. 


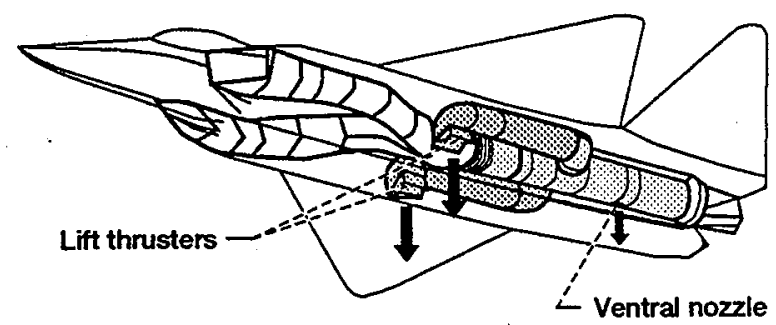

Figure 1.-Conceptual ASTOVL aircraft.

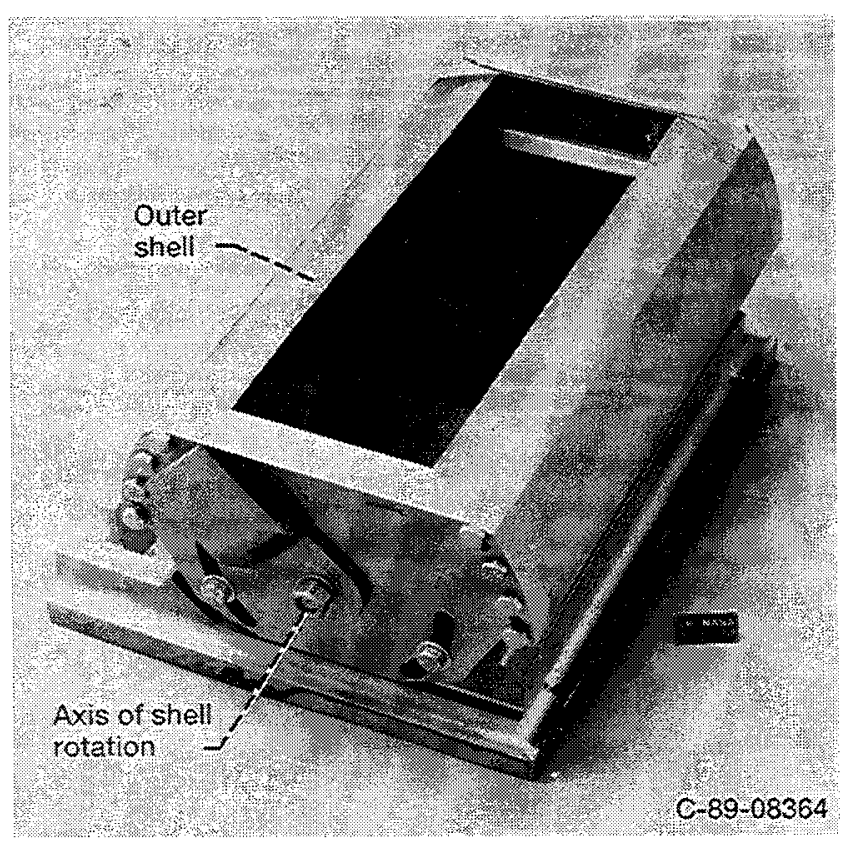

(a) In mid-position $\left(\delta_{j}=0^{\circ}\right)$.

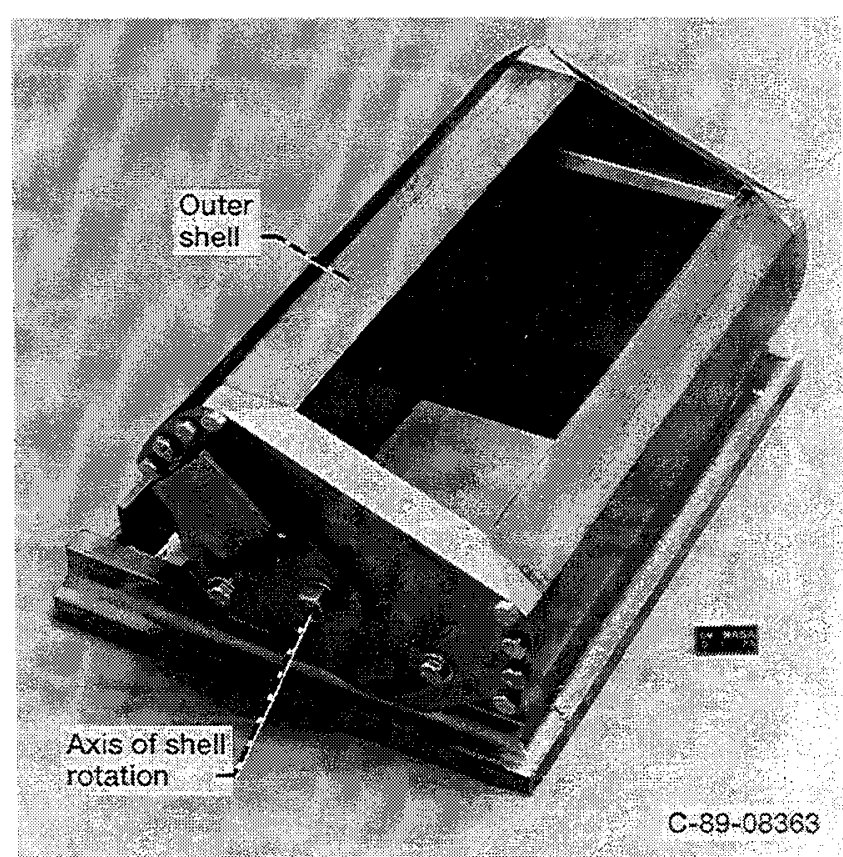

(b) In vectored position $\left(\delta_{j}=20^{\circ}\right)$.

Figure 2.-Swivel nozzle (from Ref. 4). 


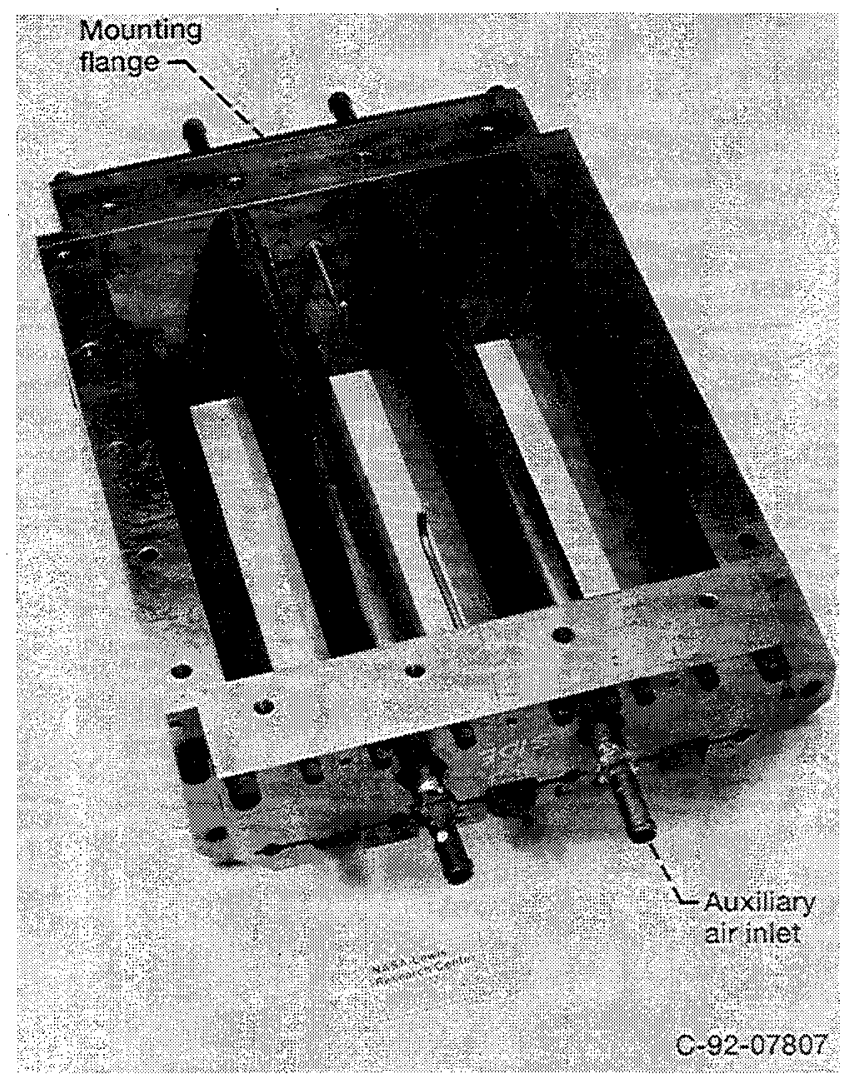

(a) View from inlet side.

Tailpipe flow direction

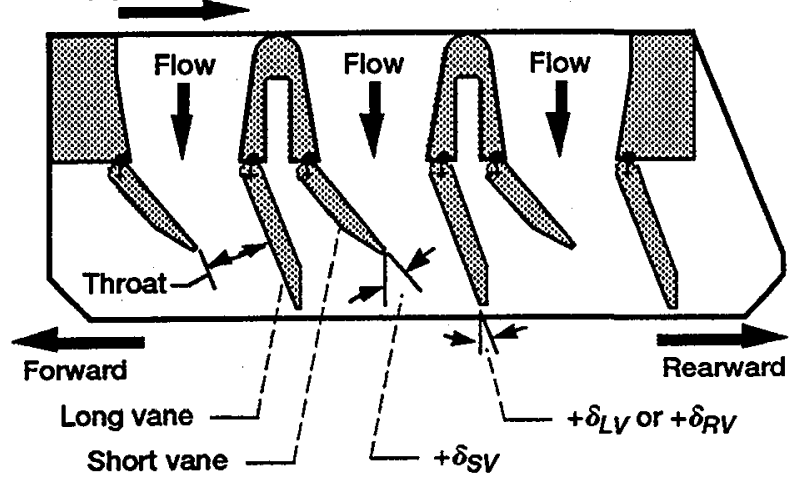

(c) Cross section showing vane arrangement.

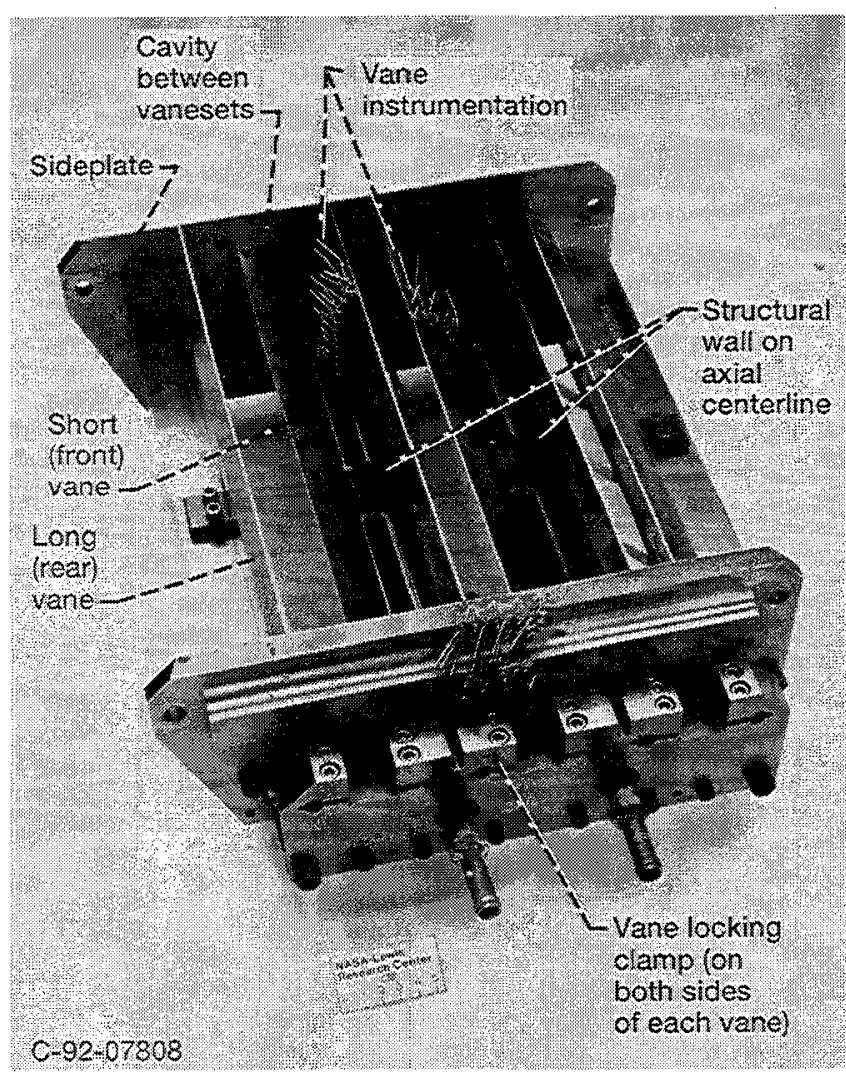

(b) View from exit side.

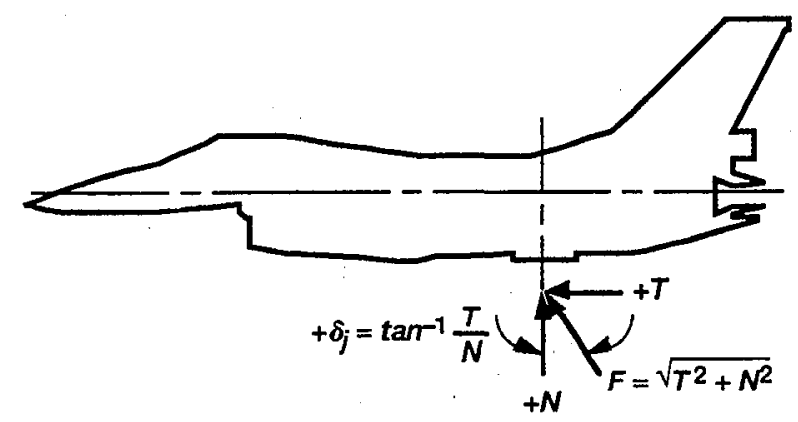

(d) Nozzle force notation.

Figure 3.-Vane nozzle. 


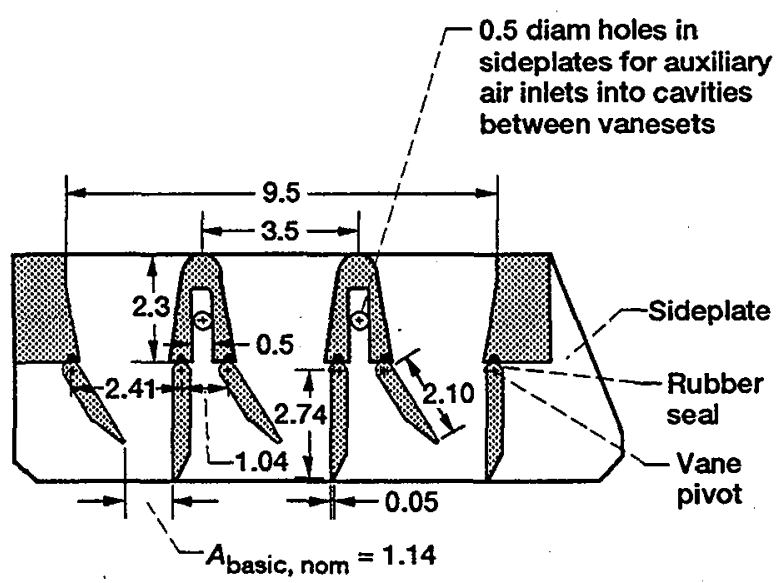

Figure 4.-Cross section of vane nozzle. (Dimensions are in inches.)
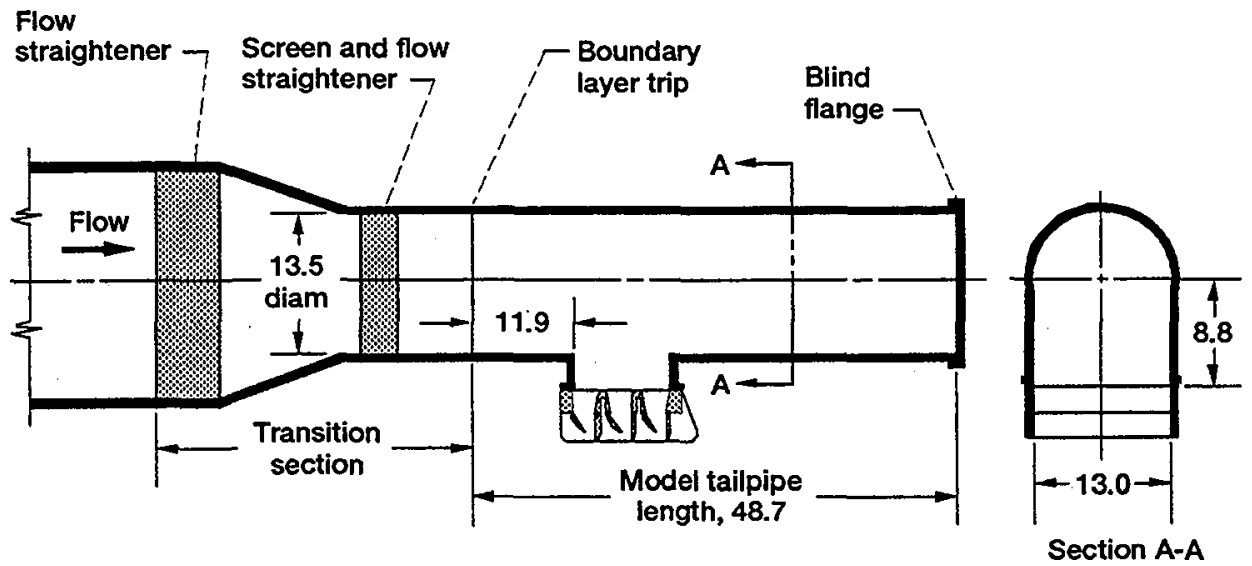

Figure 5.-Cross section of vane nozzle on model tailpipe. (Dimensions are in inches.) 


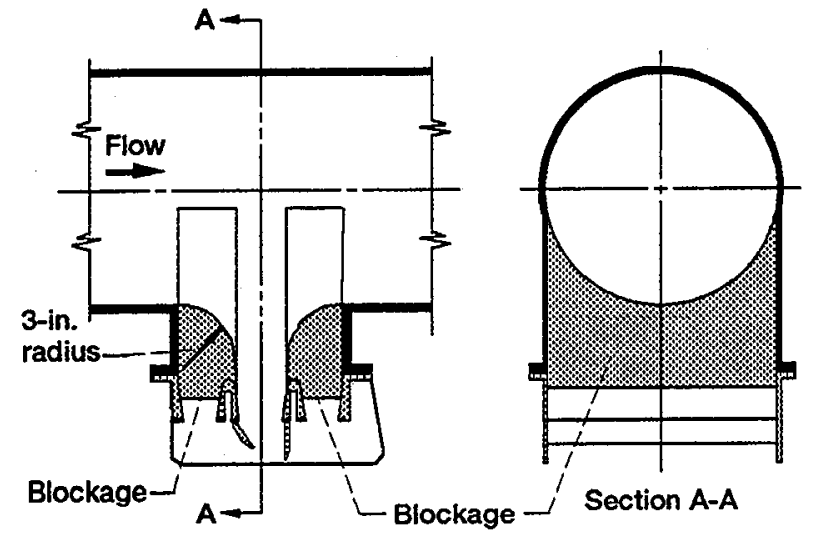

Figure 6.-Blockage in front and rear vanesets for vector tests.

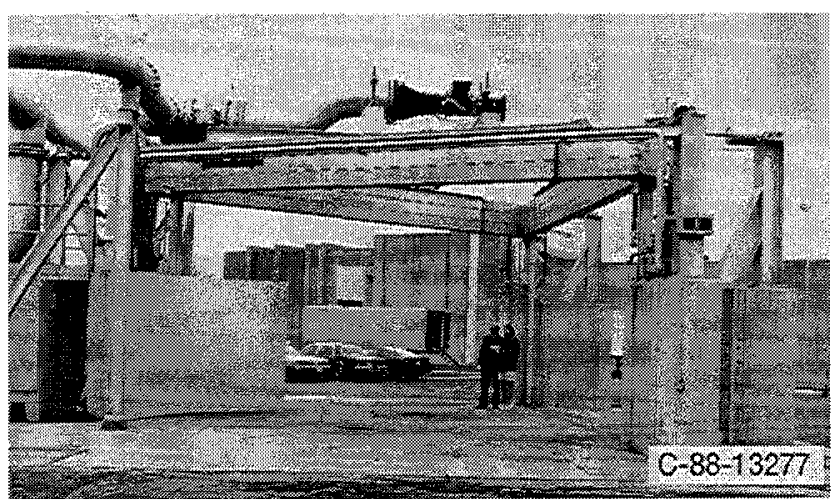

Figure 7.--Powered Lift Facility. (Since this photograph was taken, the facility has been enclosed with an acoustic dome.)

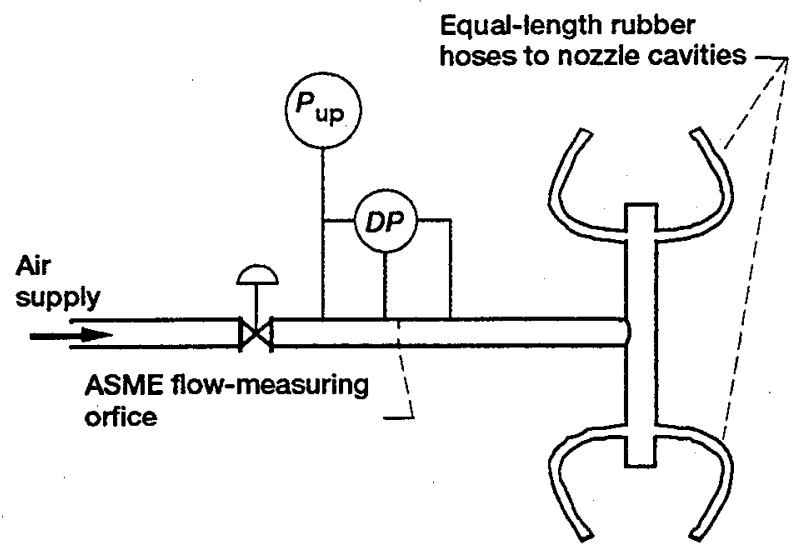

Figure 8.-Schematic diagram of auxiliary air supply. 
* Stream total pressure, center of equal area

- Wall surface static pressure

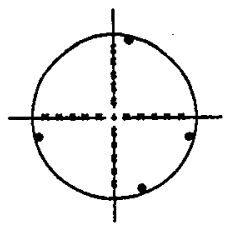

Station 5
Rear vaneset

Average for center vaneset

Front vaneset

$\left.\begin{array}{ccccc}x & x & x & x & x \\ - & - & - & - & - \\ x & x & x & x & x\end{array}\right\}$

$x \times x$.

Station 6

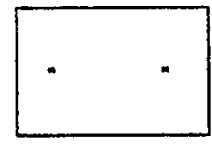

Station 6 (vector tests only)

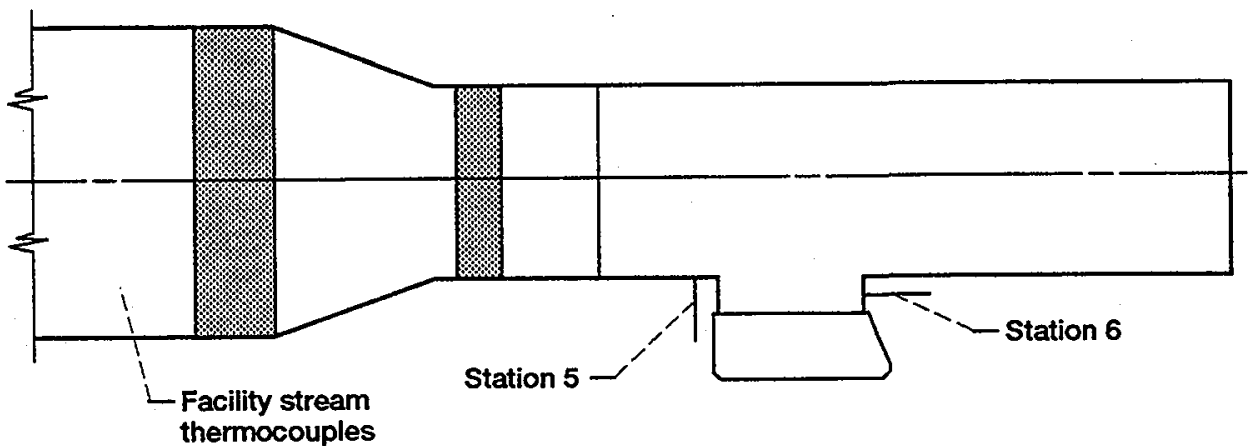

(a) Tailpipe and nozzle inlet pressures. Station cross sections drawn looking into flow.

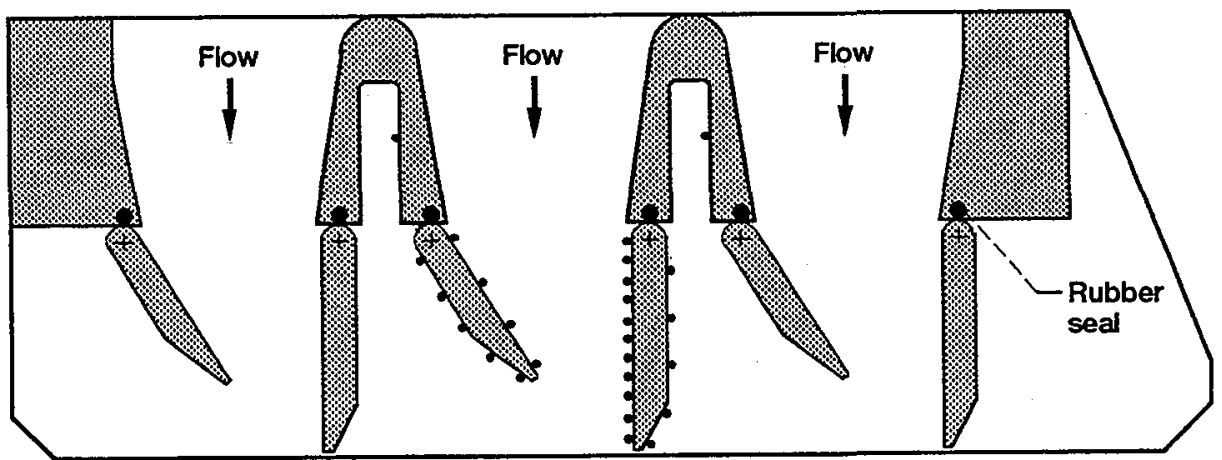

(b) Vane and cavity surface pressures.

Figure 9.-Station and instrumentation diagrams.

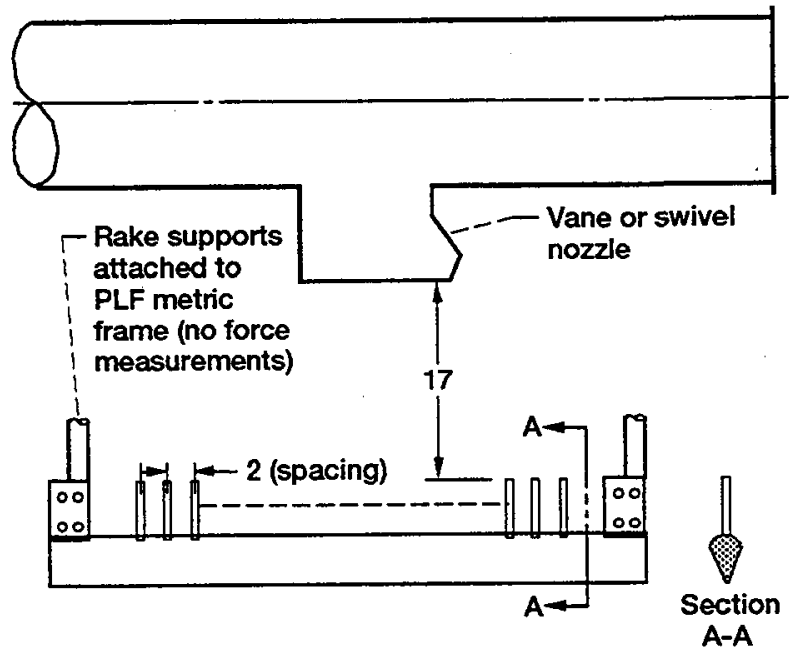

Figure 10.- Jet wake total pressure rake installation. (All dimensions are in inches.) 

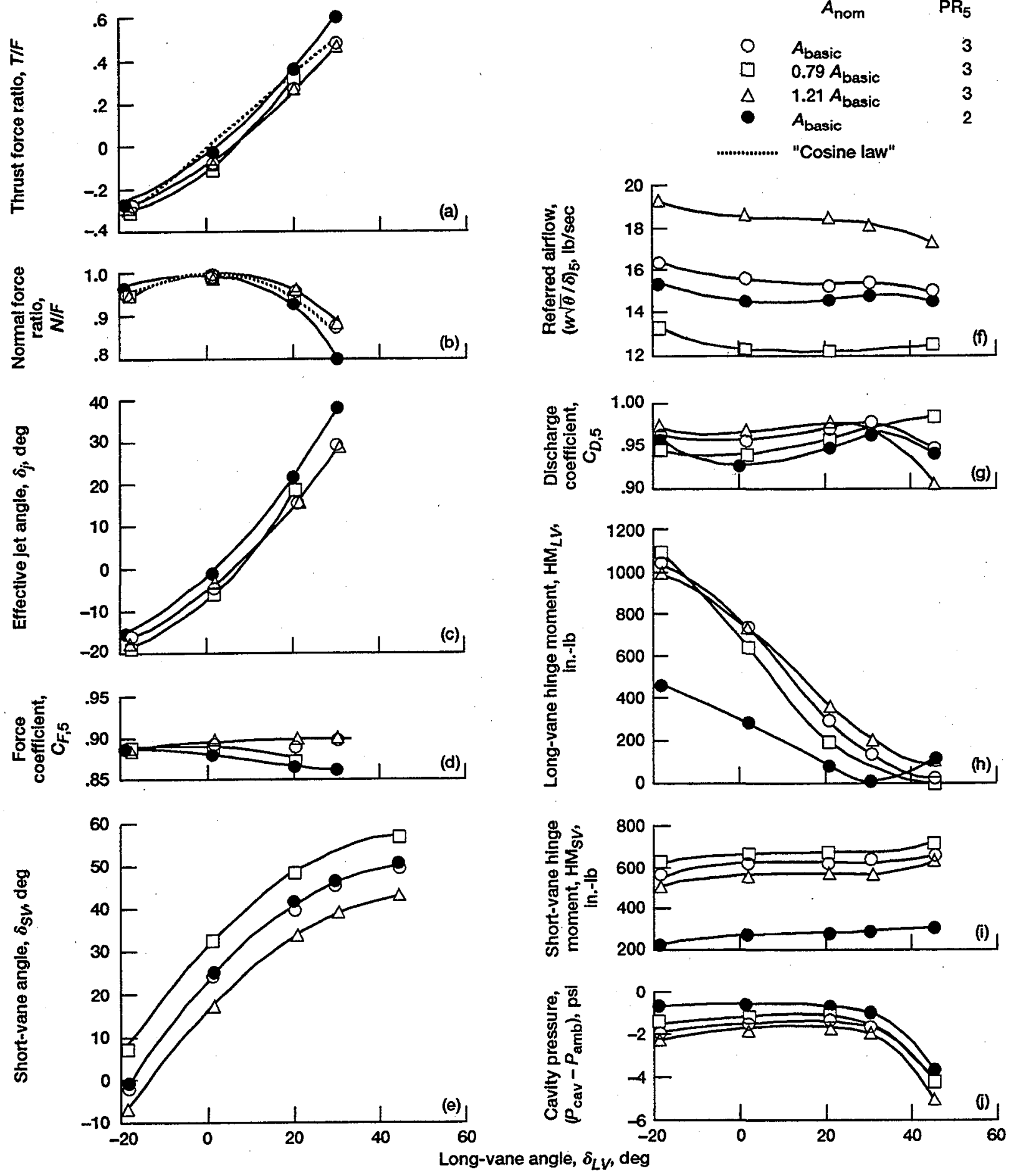

Figure 11.-Vane nozzle performance at constant tailpipe-to-ambient pressure ratio. 

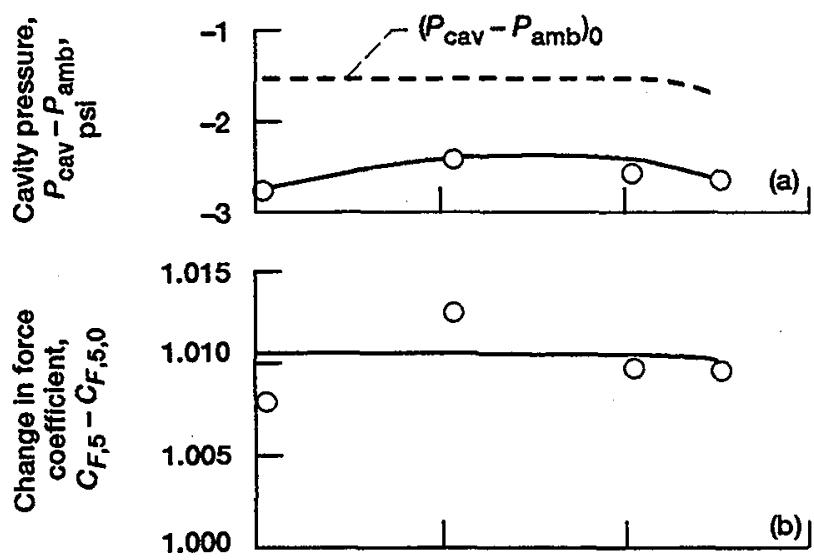

(b)
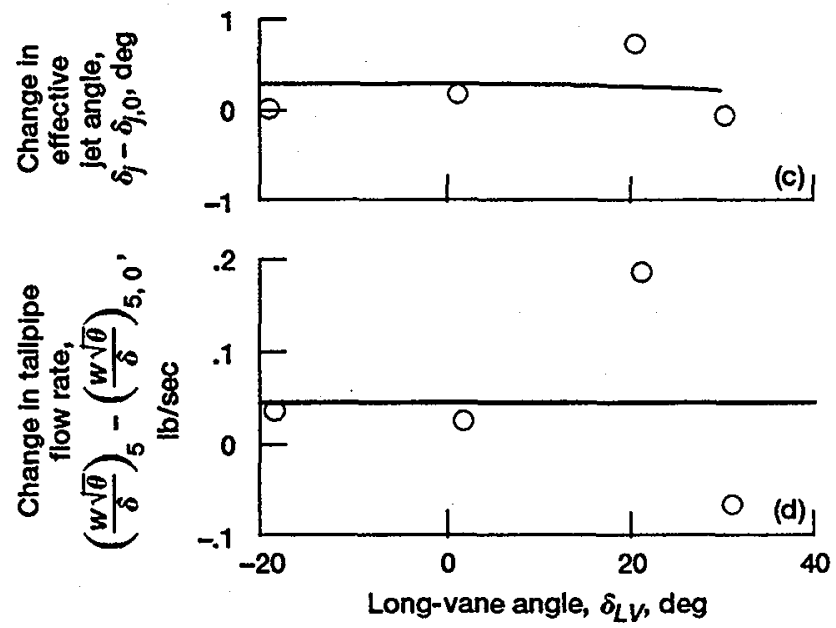

Figure 12.-Performance when air was pumped equally into each of the four cavities. Pumped flow ratio, 1.5 percent; nominal throat area, $A_{\text {basic }}$; tailpipe-to-ambient pressure ratio, $\mathrm{PR}_{5}, 3$.

\section{Tailpipe-to- ambient \\ pressure \\ ratio,}

$\mathrm{PR}_{5}$
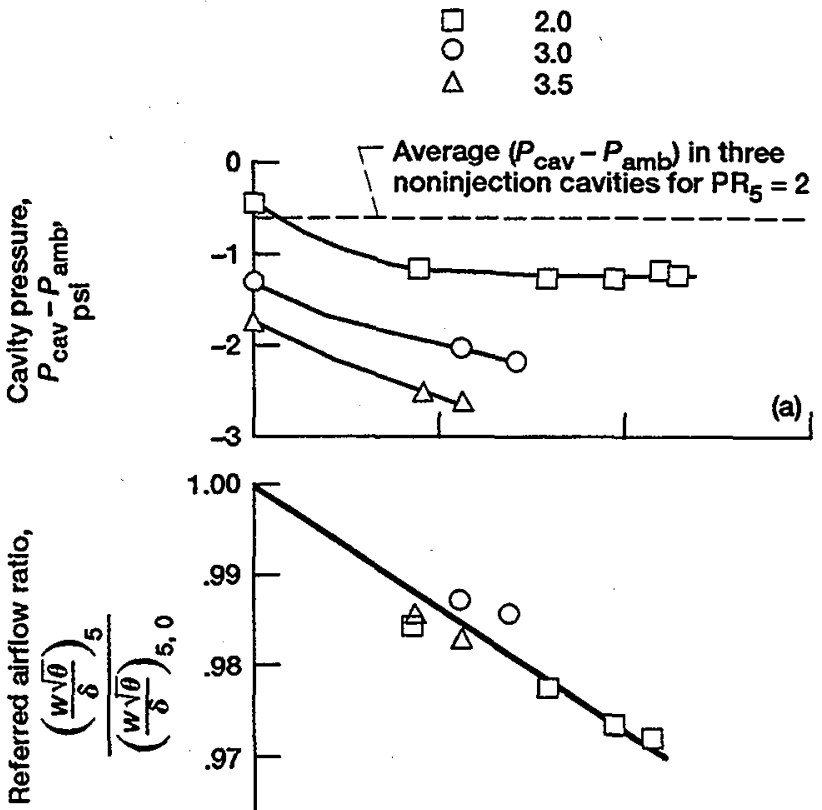

1.00
.99
.98
.97
.96

(a)
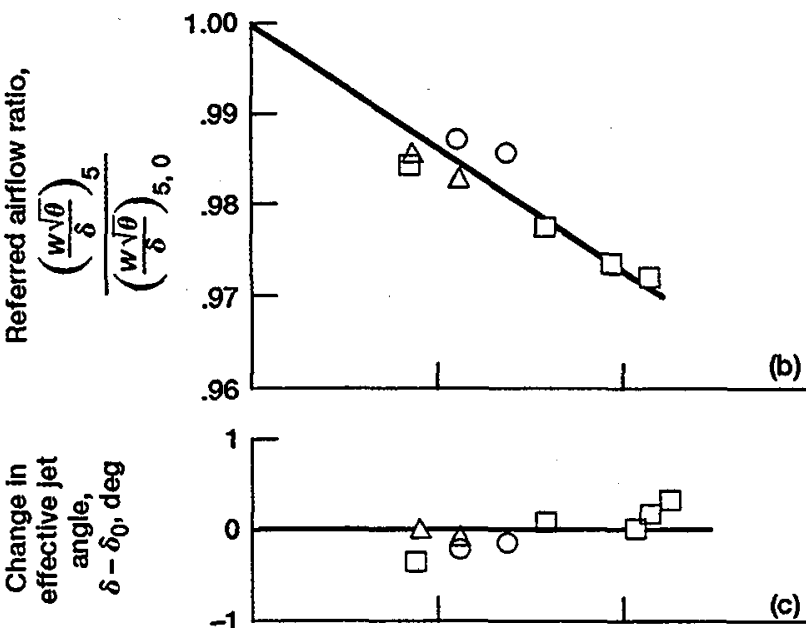

(c)

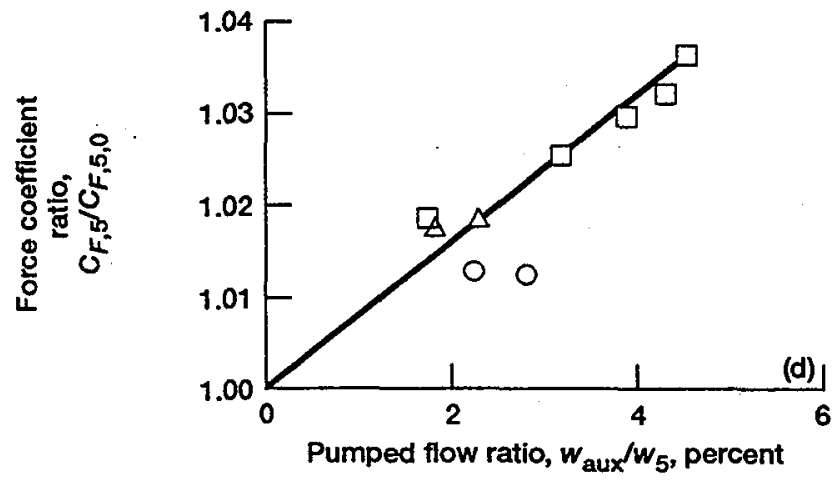

Figure 13.-Pumping performance when all pumped flow was ingested into one of the four cavities. Nominal long-vane angle, $0^{\circ}$; nominal flow area, $A_{\text {basic. }}$ 

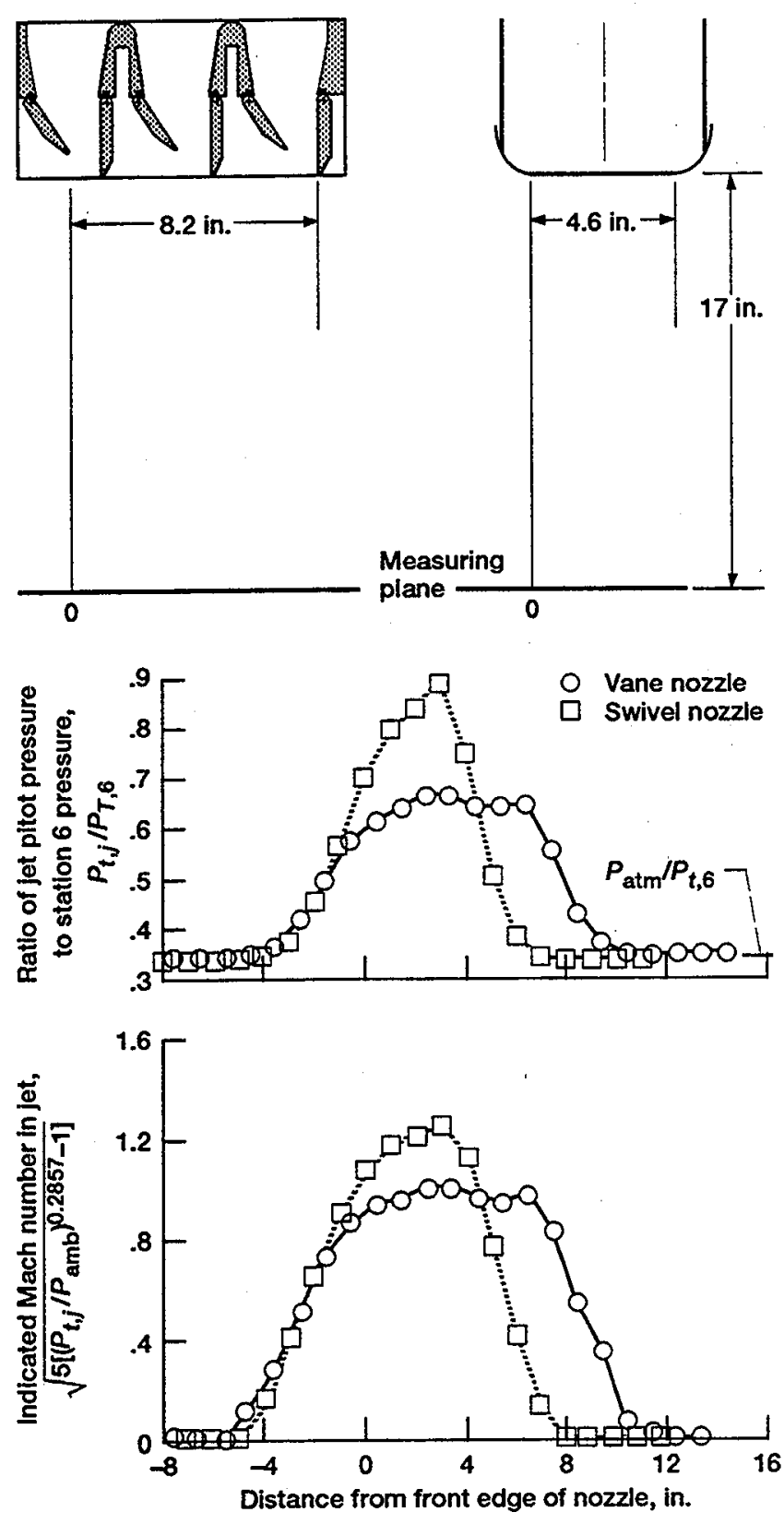

Figure 14.-Comparison of free jet wakes. Tailpipe pressure ratio, $\mathrm{PR}_{5}, 3$.

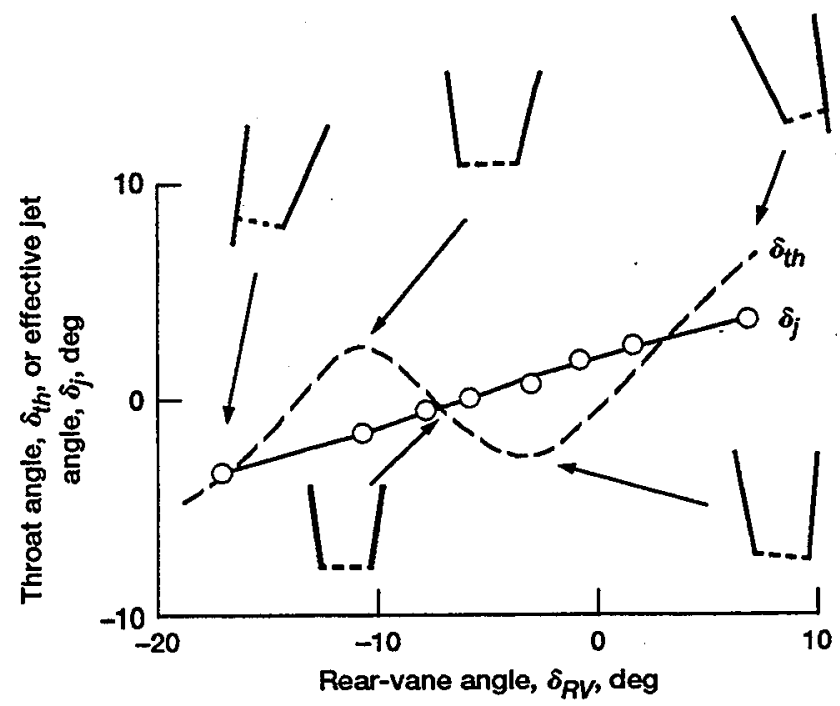

Figure 15.-Vector characteristics of single vaneset with long/long vanes. Nozzle pressure ratio, 3.0; nominal throat area, $A_{\text {basic. }}$

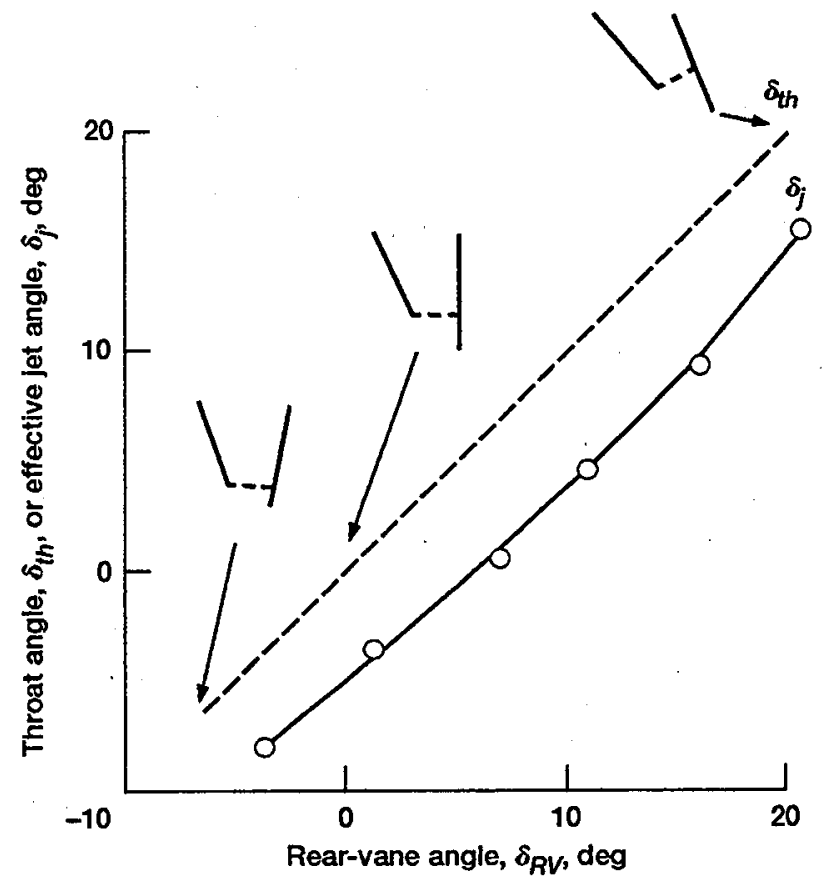

Figure 16.-Vector characteristics of single vaneset with long rear vane and short front vane. Nozzle pressure ratio, 3.0; nominal throat area, $A_{\text {basic }}$. 

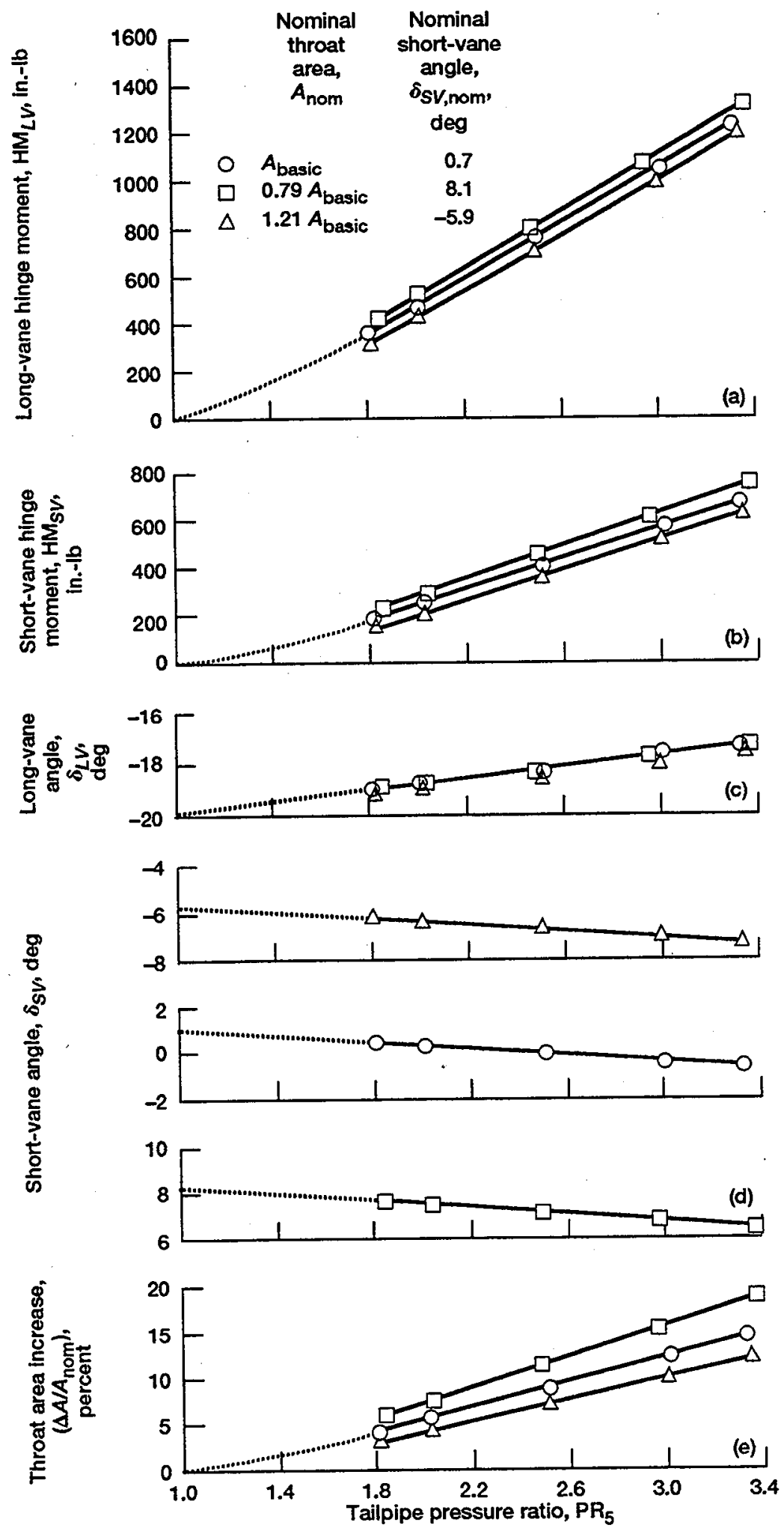

Figure B-1.-Measured performance at $-20^{\circ}$ nominal long-vane angle. 

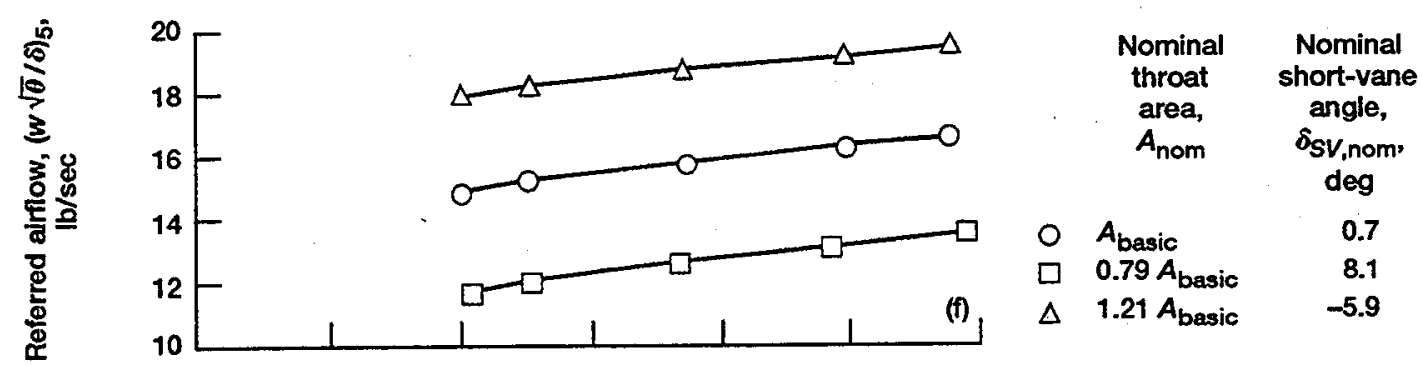

总志

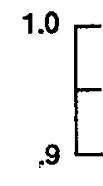

(g)

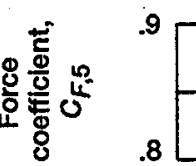

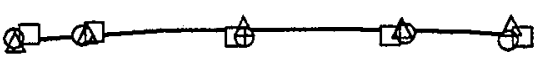

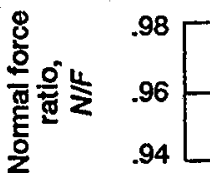

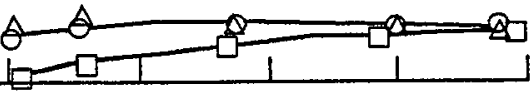

总
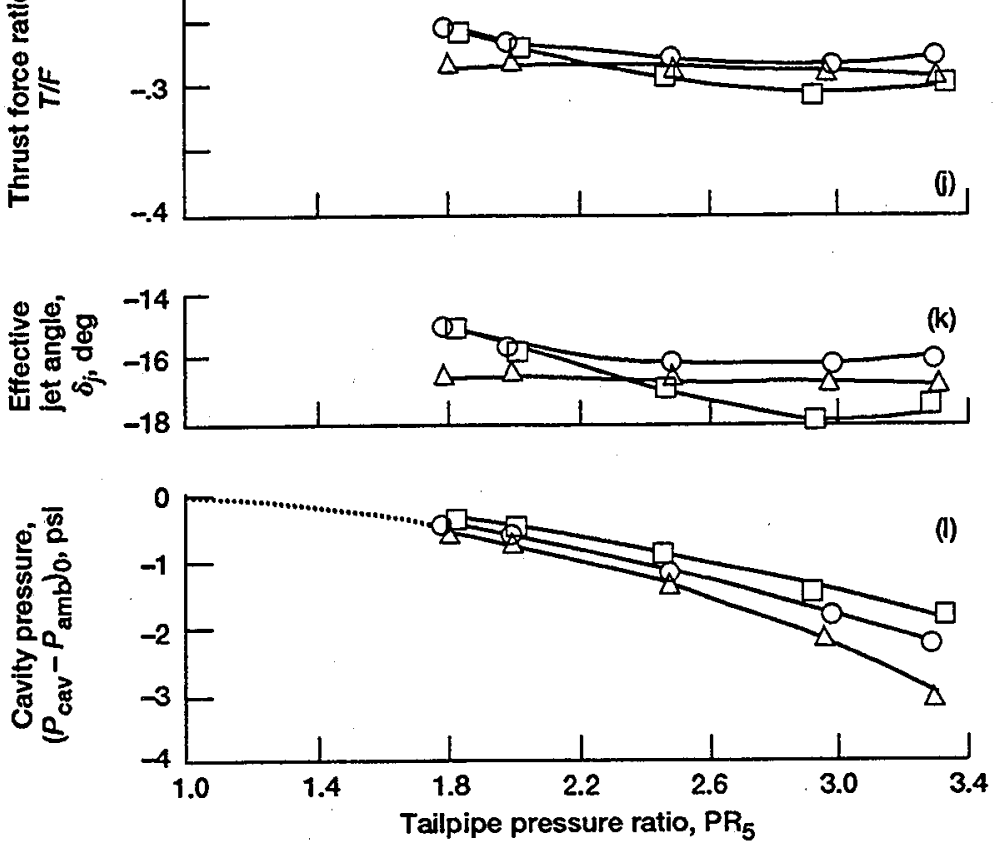

Figure B-1.-Concluded. 

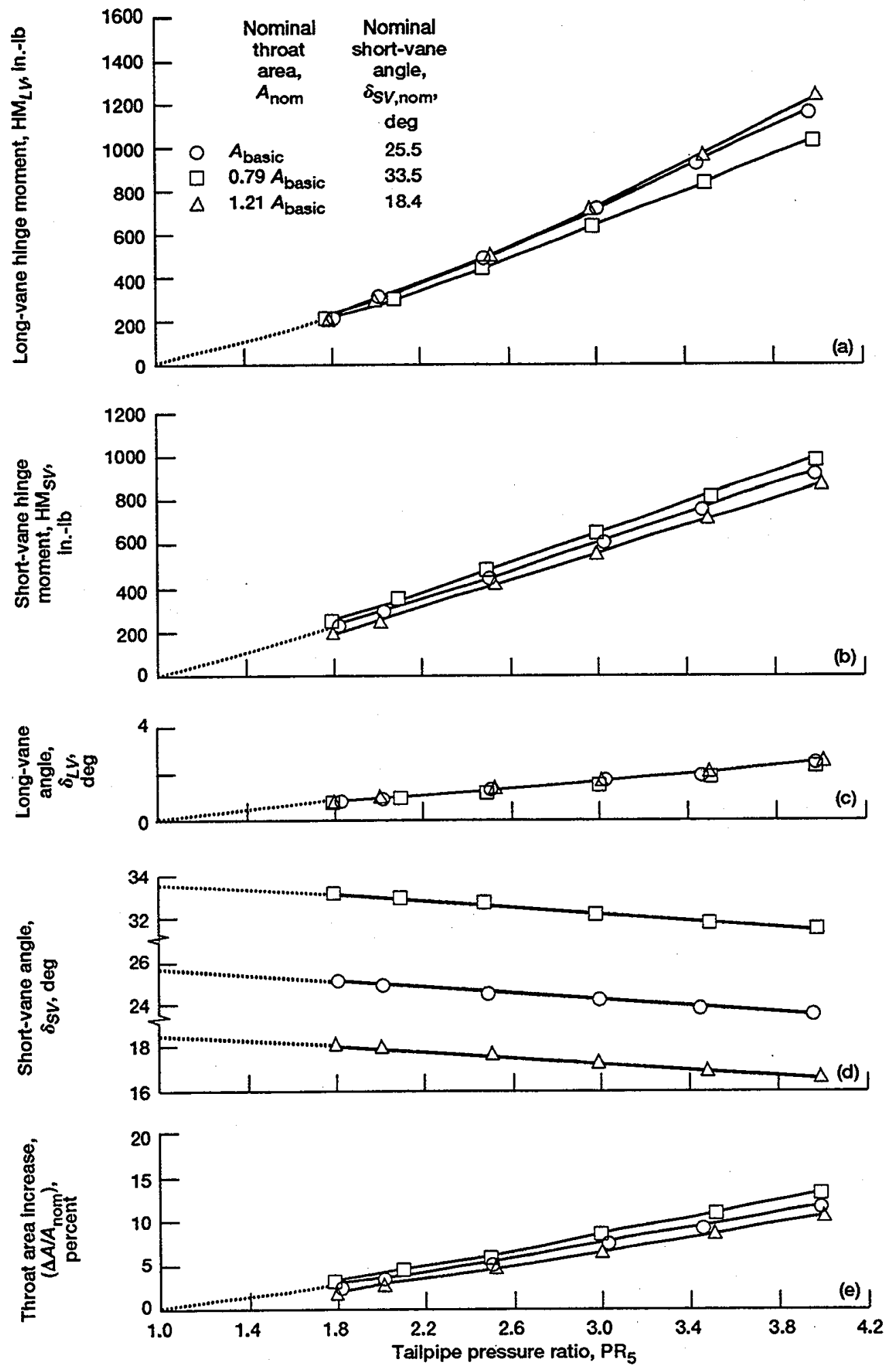

Figure B-2.-Measured performance at $0^{\circ}$ nominal long-vane angle. 

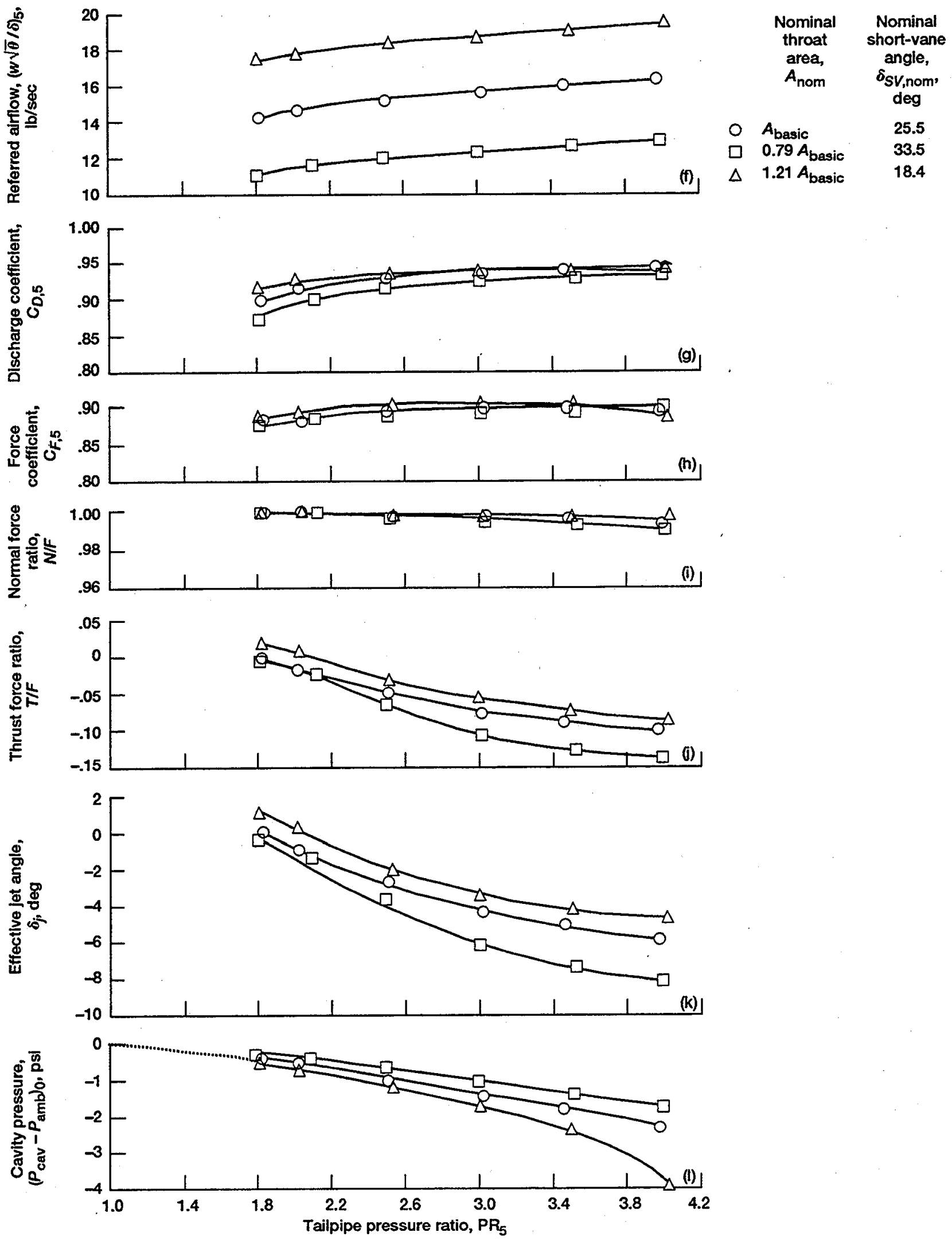

Figure B-2.-Concluded. 

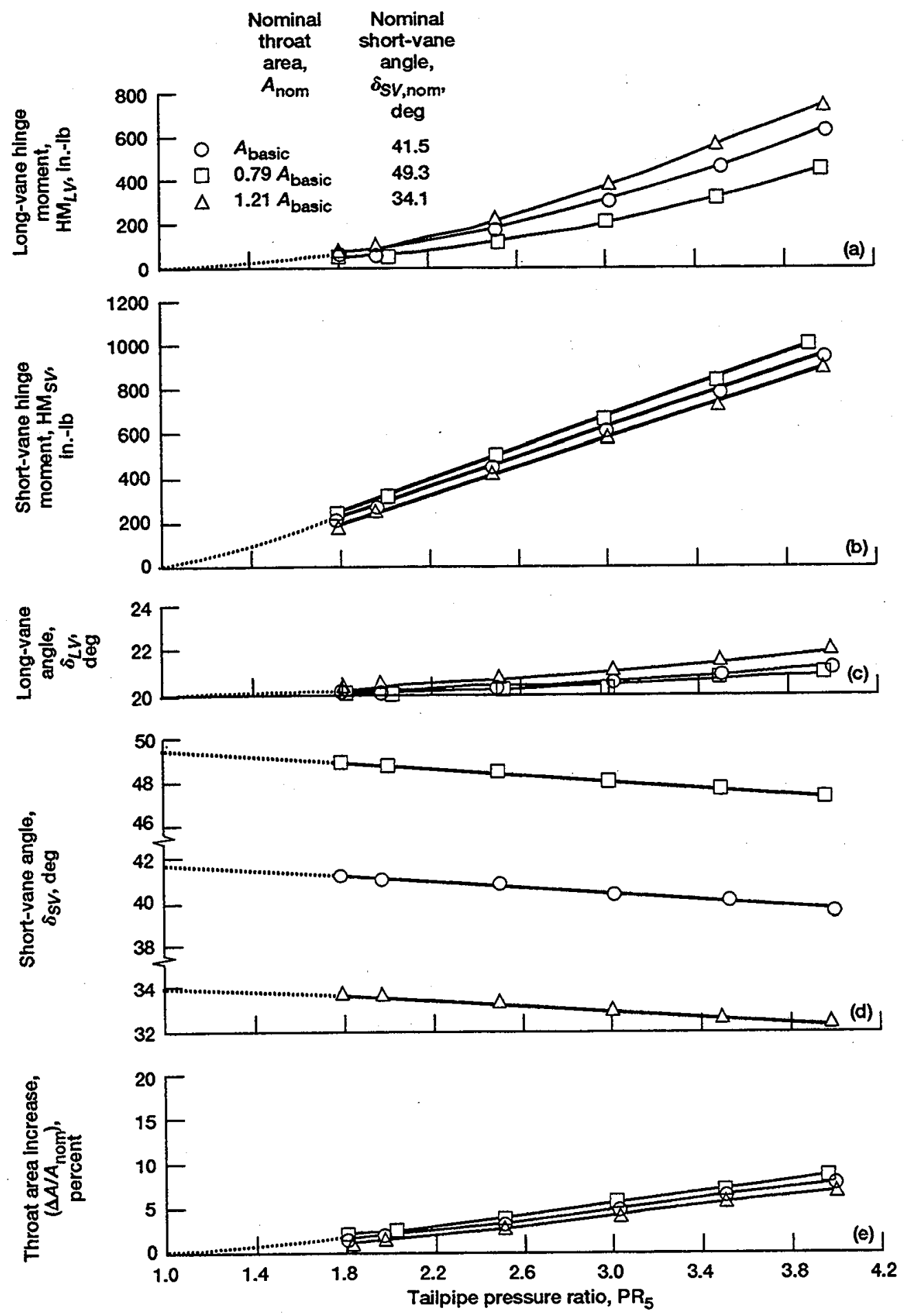

Figure B-3.-Measured performance at $20^{\circ}$ nominal long-vane angle. 


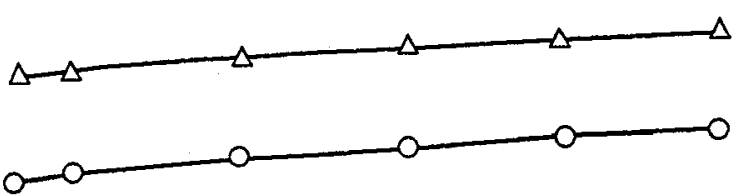

$A_{\text {nom }}$

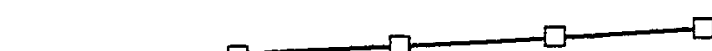

- A basic

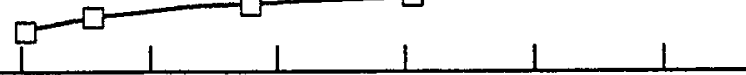

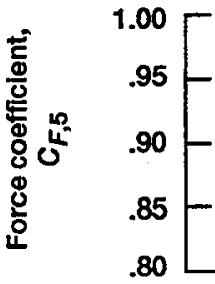
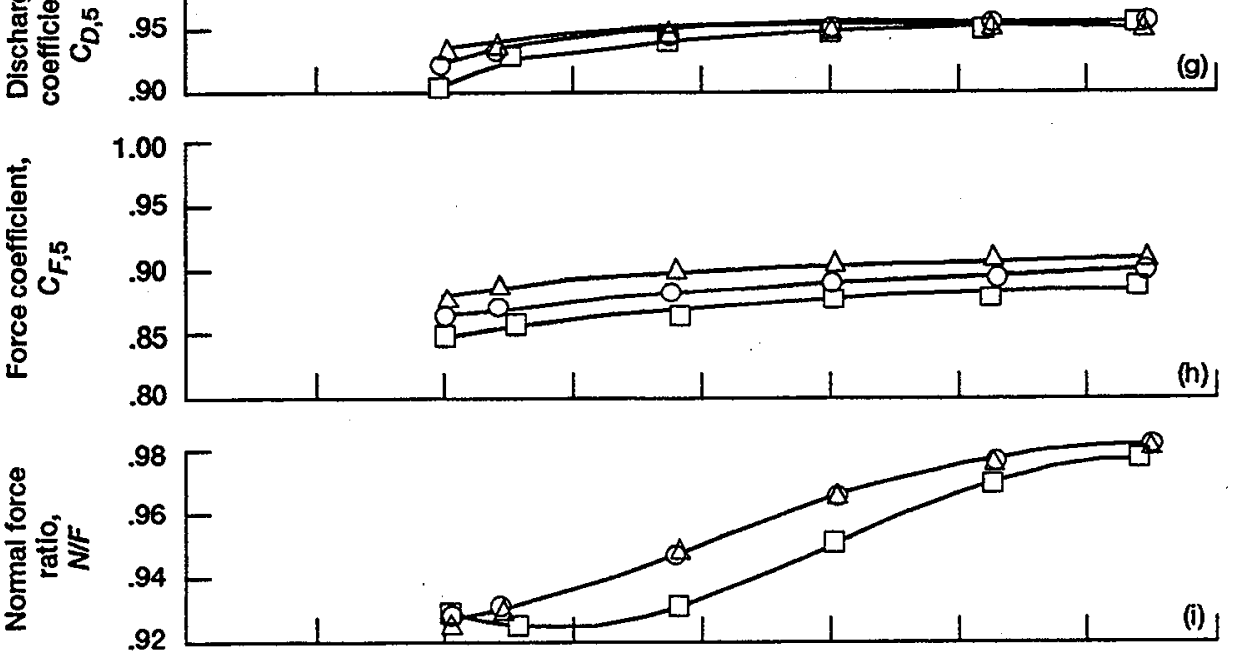

害
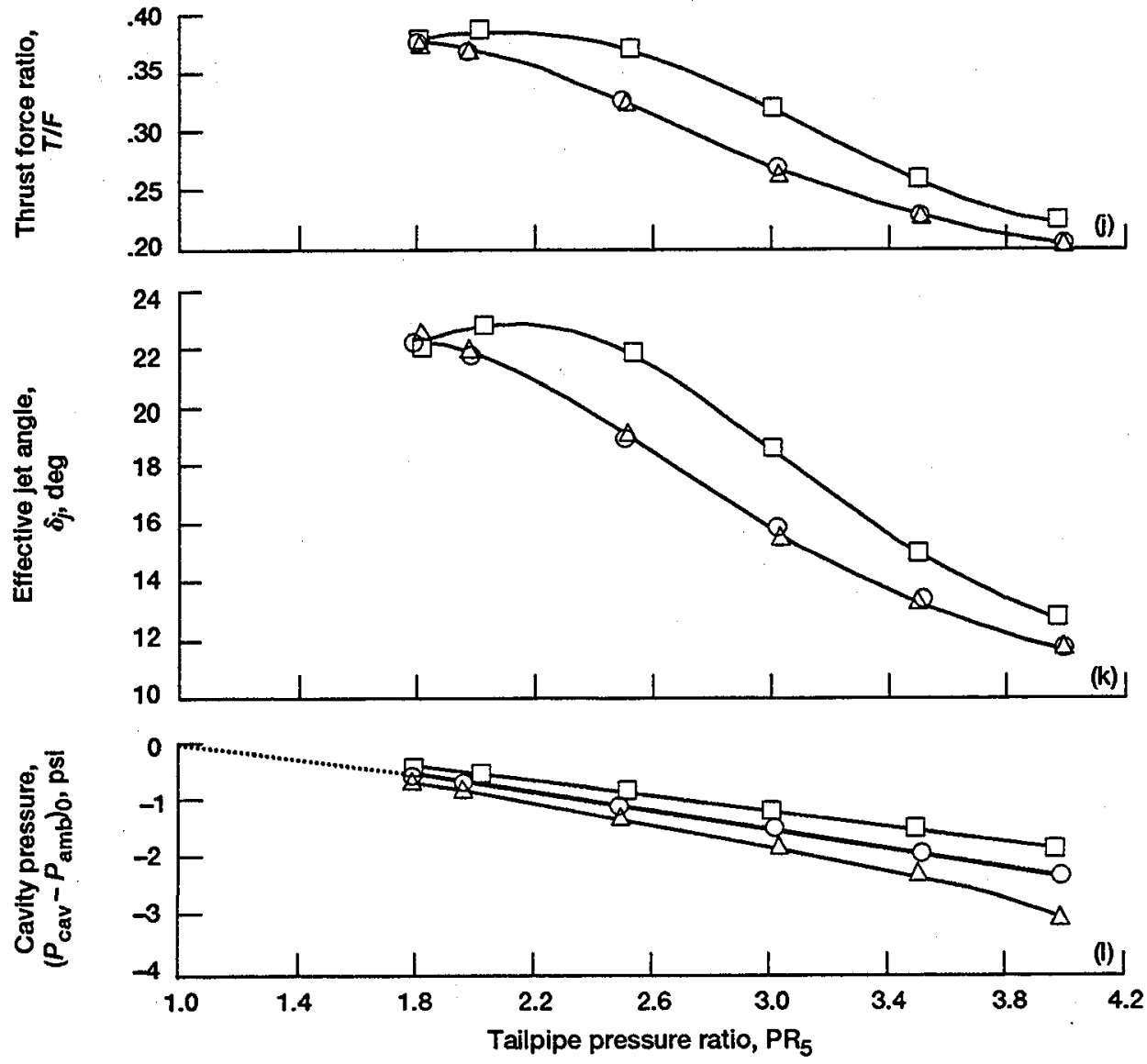

Figure B-3.-Concluded. 

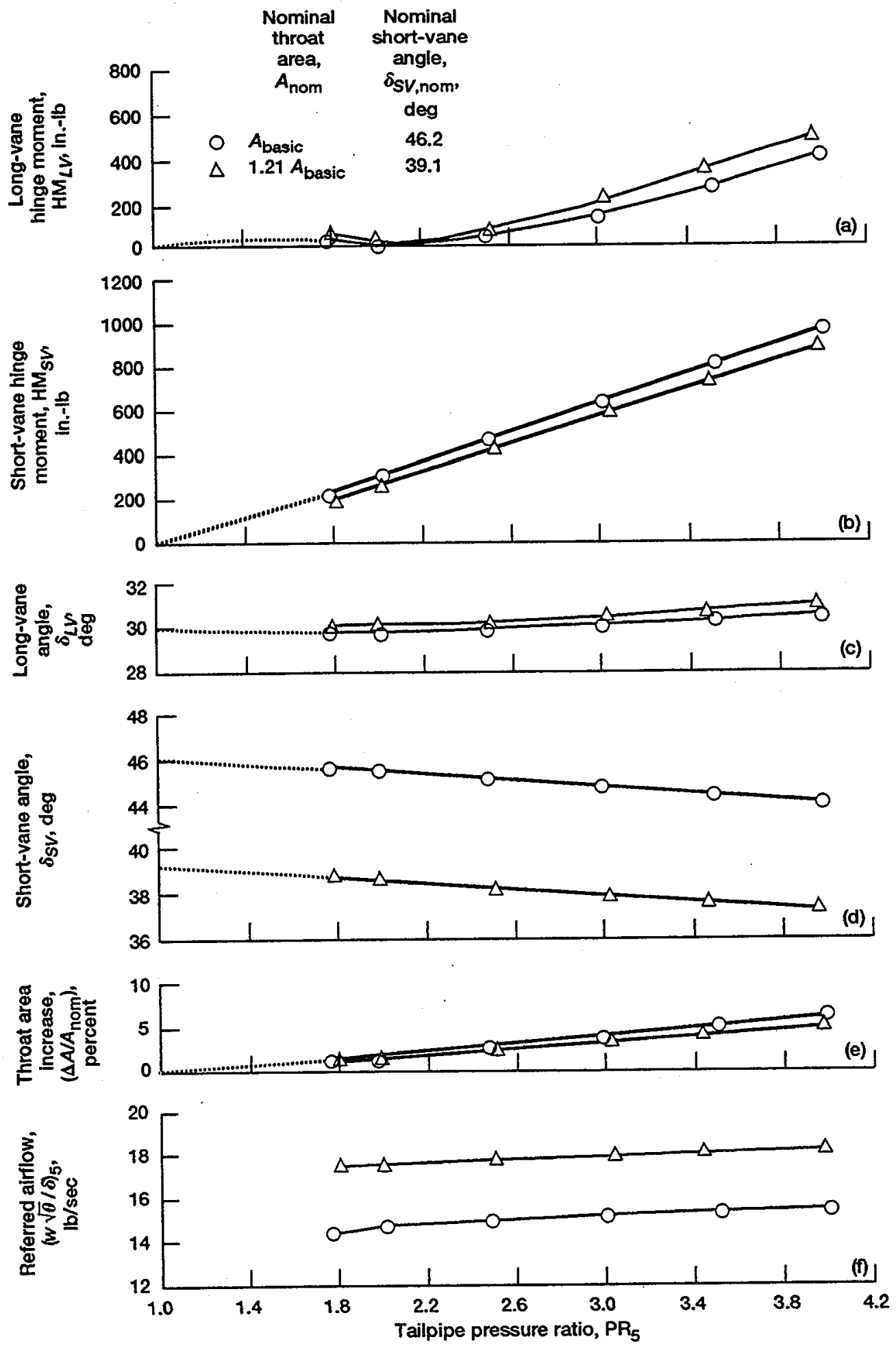

Figure B-4.-Measured performance at $30^{\circ}$ nominal long-vane angle. 


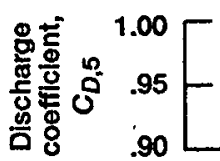

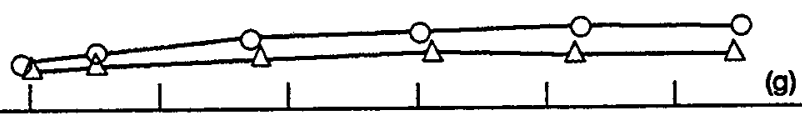

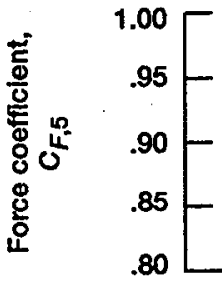

- $A_{\text {basic }}$
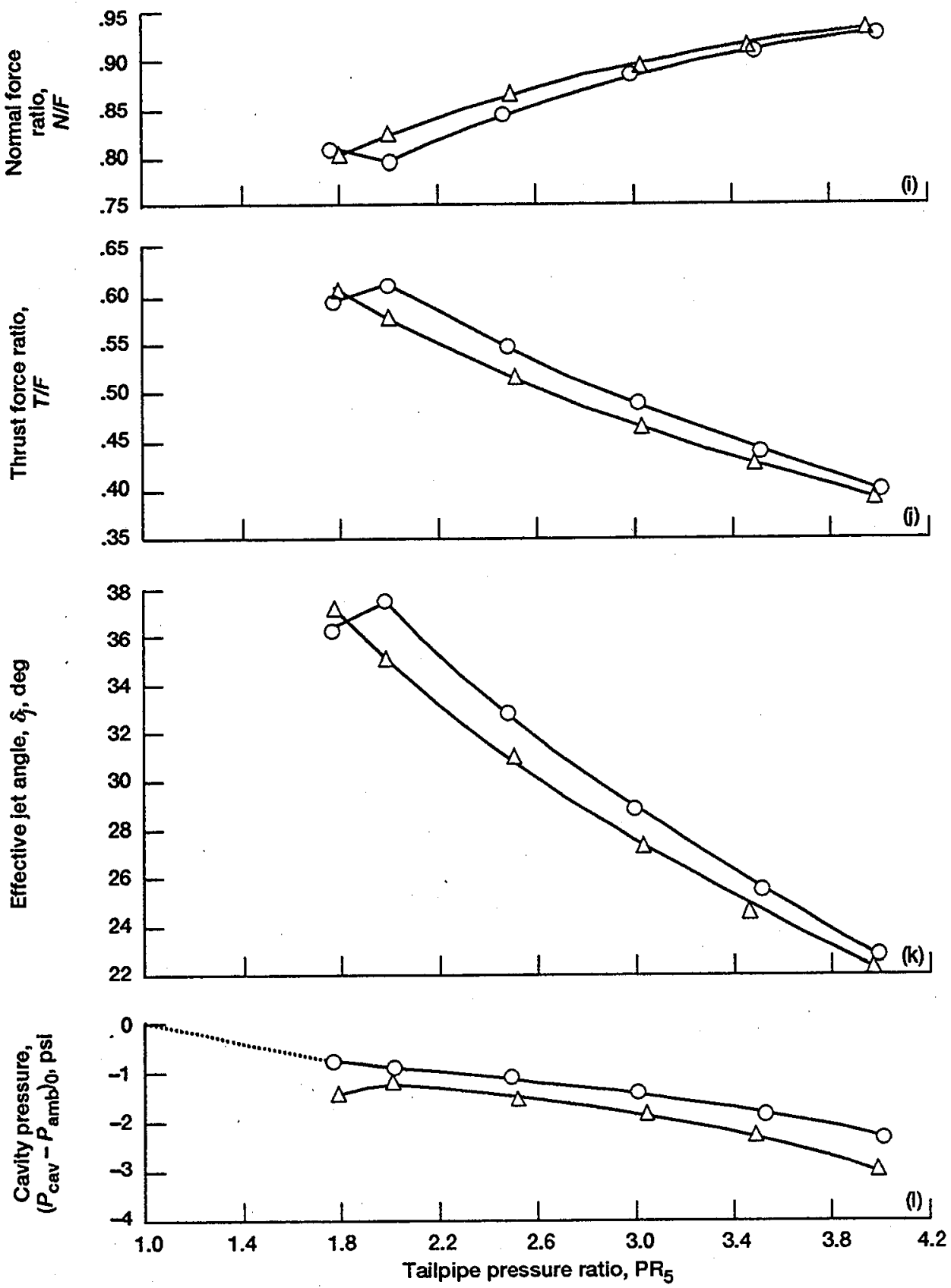

Figure B-4.-Concluded. 

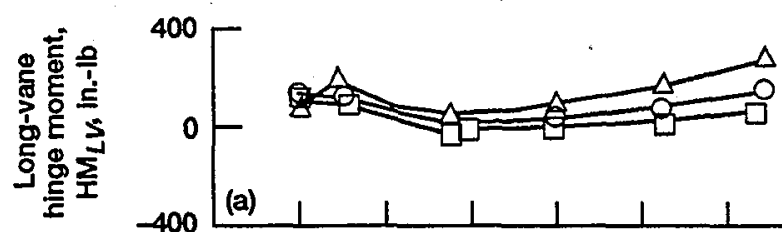

(a)

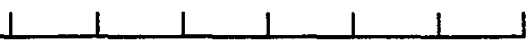

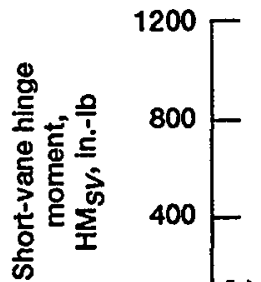

(b)

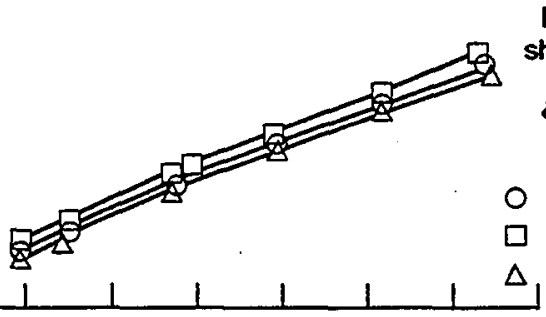

Nominal Nominal

short-vane throat

angle,

$\delta_{\text {SV, nom, }}$

area,

deg

$50.4 \quad A_{\text {basic }}$

$\quad 0.79 A_{\text {basic }}$

$43.1 \quad 1.21 A_{\text {basic }}$

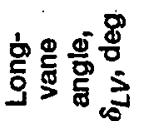

${ }^{48}$

(c)
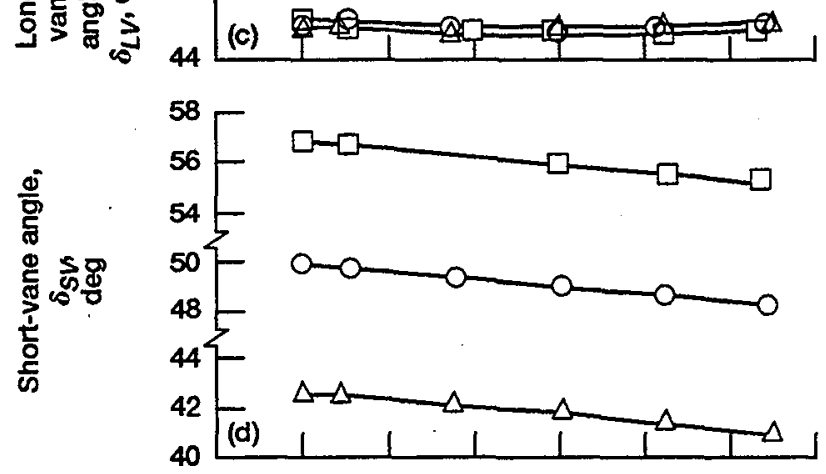

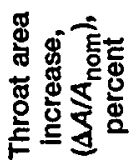

10
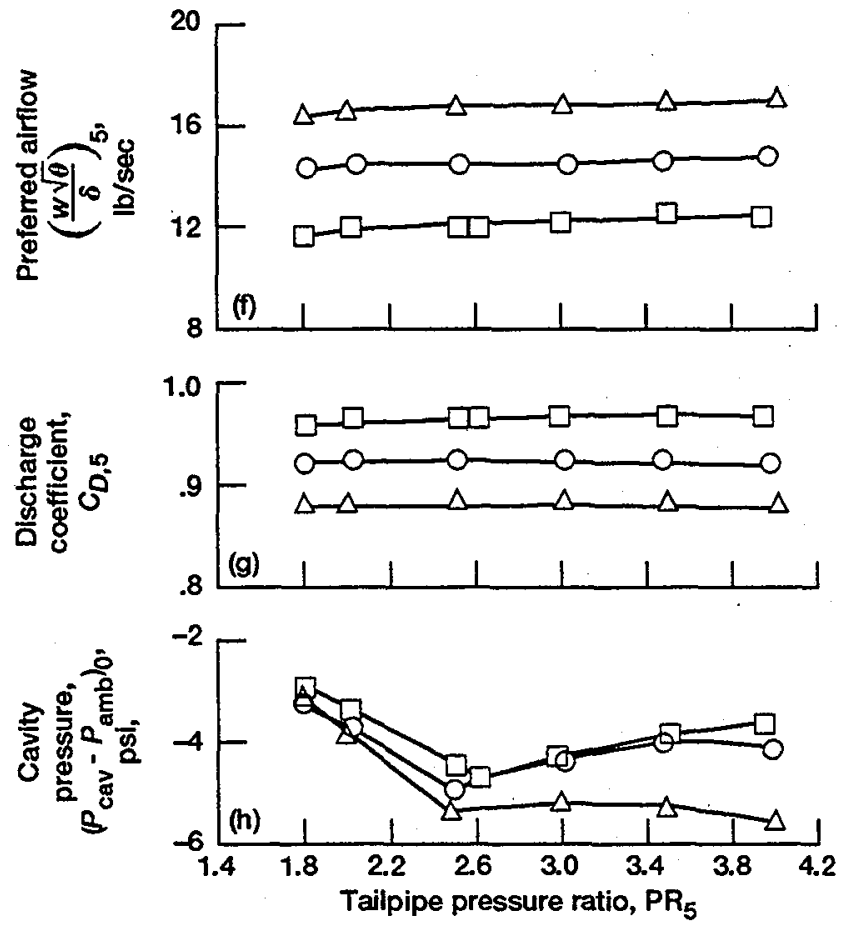

Figure B-5.-Measured performance at $45^{\circ}$ nominal long-vane angle. 


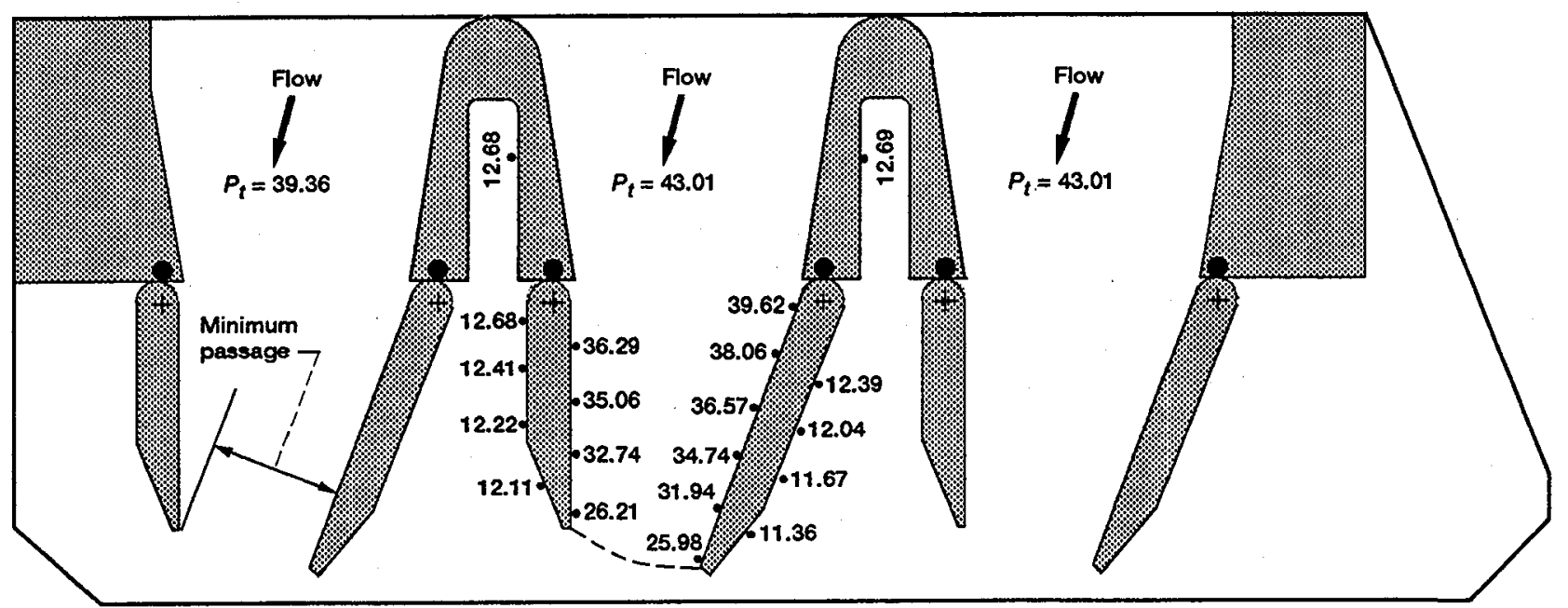

(a) Nominal long-vane angle, $-20^{\circ} ; \mathrm{PR}_{5}, 3.01 ; P_{\mathrm{amb}}, 14.34 \mathrm{psia}$.

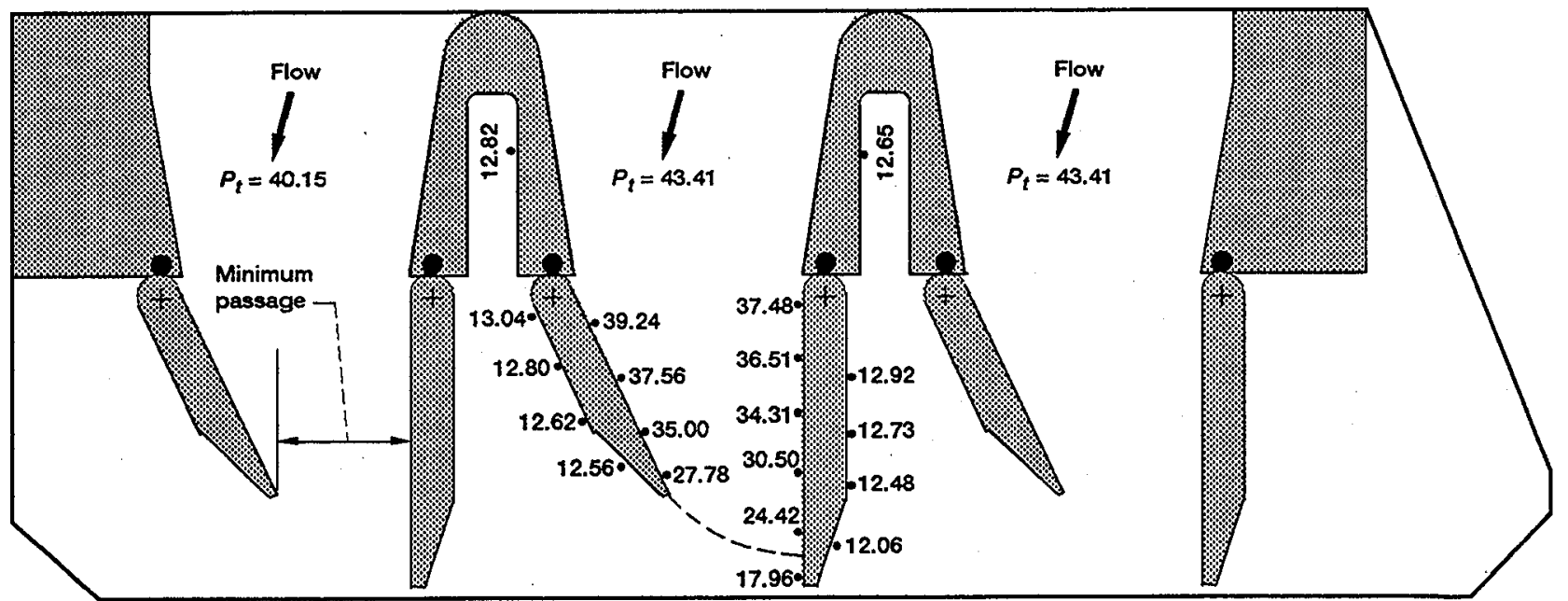

(b) Nominal long-vane angle, $0^{\circ} ; \mathrm{PR}_{5}, 3.03 ; P_{\mathrm{amb}}, 14.38 \mathrm{psia}$.

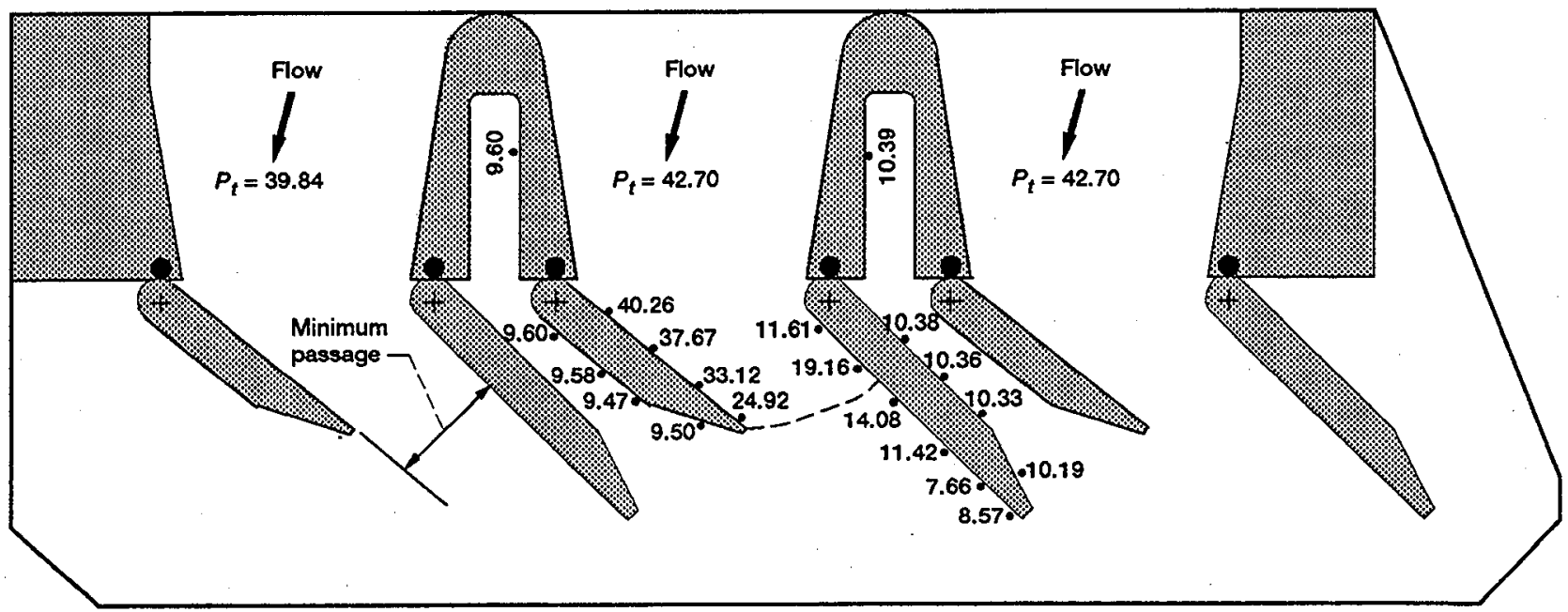

(c) Nominal long-vane angle, $45^{\circ} ; \mathrm{PR}_{5}, 3.01 ; P_{\mathrm{amb}}, 14.22$ psia.

Figure B-6.-Surface pressure measured in vane nozzle performance tests for $A_{\text {basic }}$ configurations. (Pressures are in pounds per square inch absolute. Dashed lines show location of throat from surface pressures. Tailpipe flow from left to right.) 


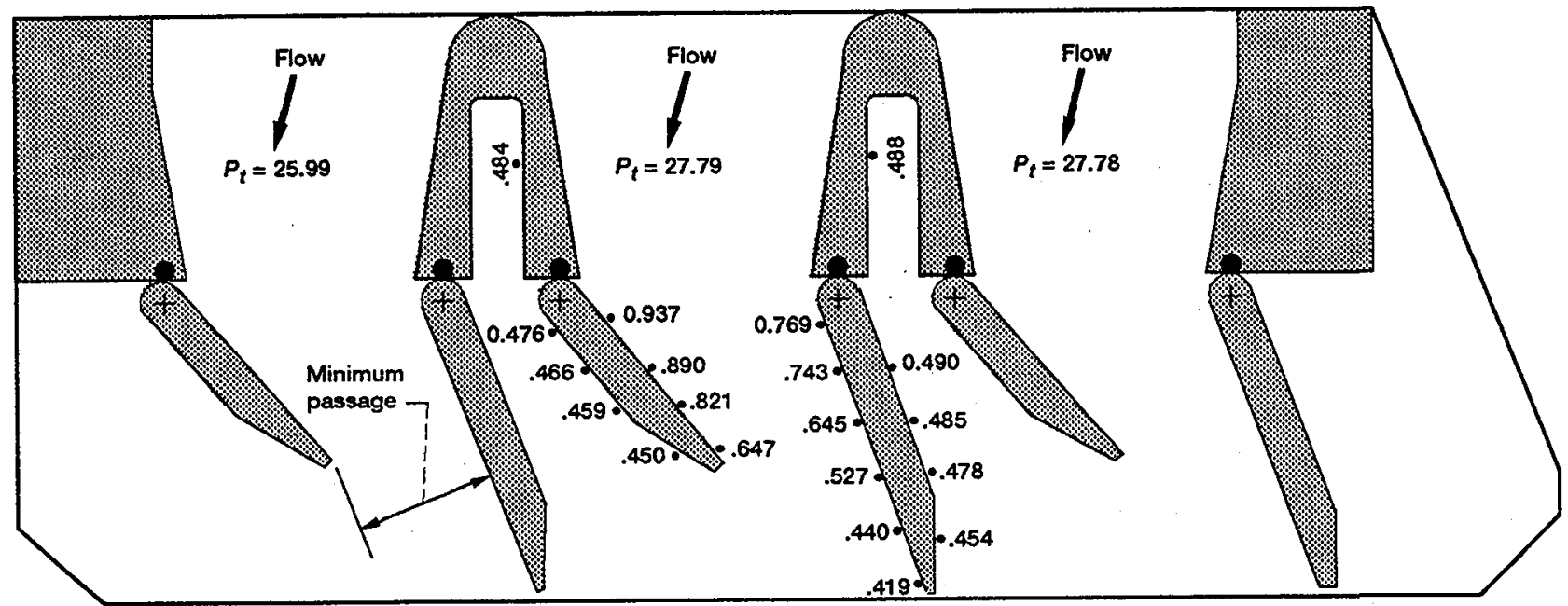

(a) $P R_{5}=1.96 ; T / F=0.37 ; N / F=0.93$

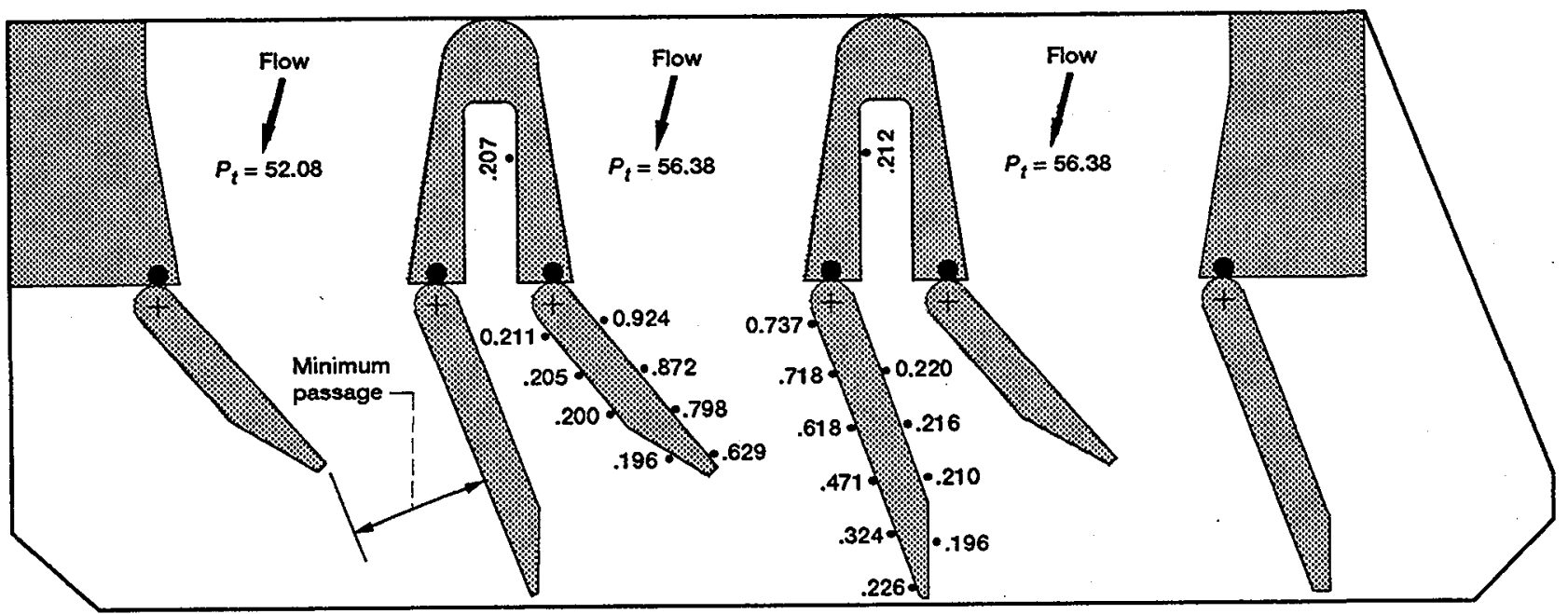

(b) $\mathrm{PR}_{5}=3.98 ; \mathrm{T} / F=0.20 ; N / F=0.98$.

Figure B-7.-Vane surface pressure divided by inlet total pressure. Nominal throat area, $A_{\text {basic }} ; \delta_{L V, \text { nom }}, 20^{\circ}$; inlet total pressure, $P_{t}$, psia; $P_{\text {amb }}, 14.18$ psia (Tailpipe flow from left to right.) 


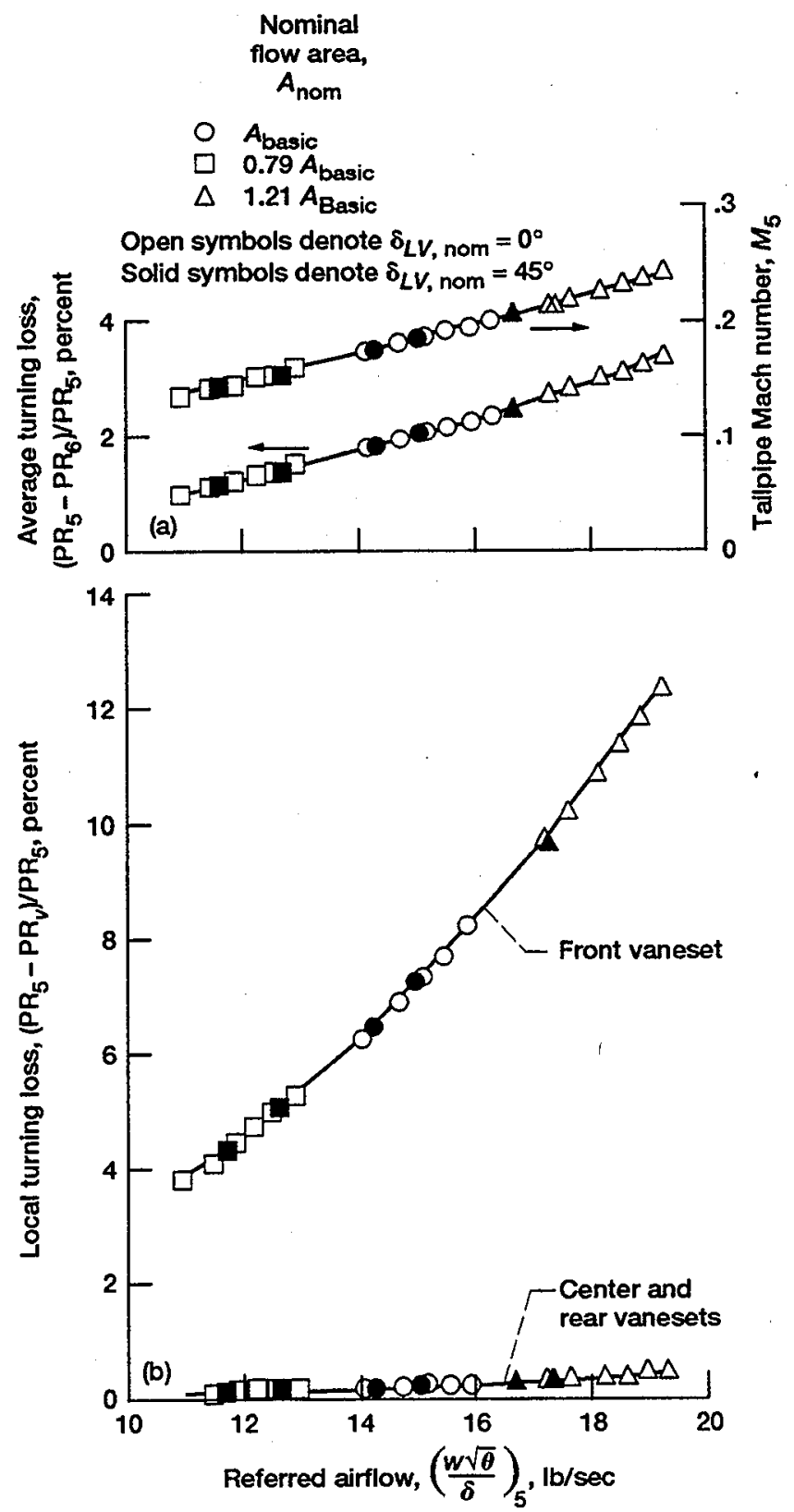

Figure B-8.-Flow-turning loss. 

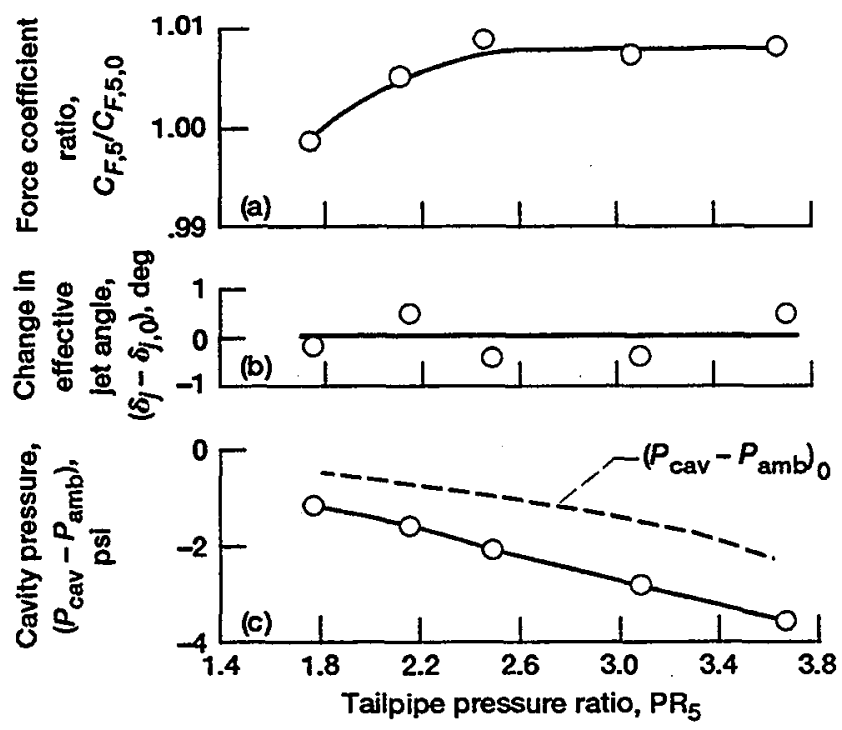

Figure C-1.-Performance with pumped air for nominal longvane angle of $-20^{\circ}$. Pumped flow ratio, 1.5 percent; nominal throat area, $A_{\text {basic }}$

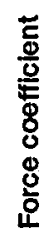
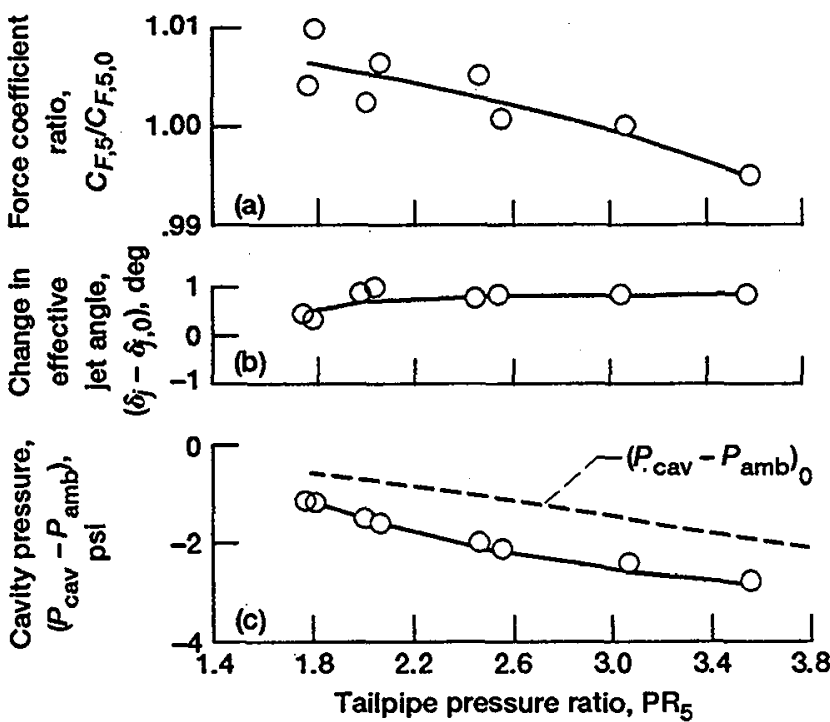

Figure C-3.-Performance with pumped air for nominal longvane angle of $20^{\circ}$. Pumped flow ratio, 1.5 percent; nominal throat area, $A_{\text {basic }}$.
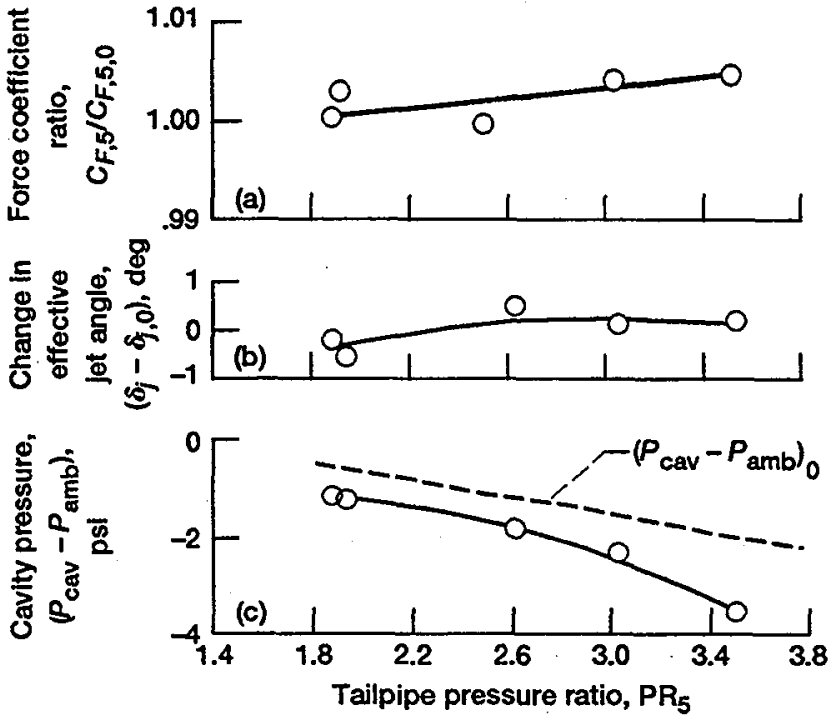

Figure C-2.-Performance with pumped air for nominal longvane angle of $0^{\circ}$. Pumped flow ratio, 1.5 percent; nominal throat area, $A_{\text {basic }}$.
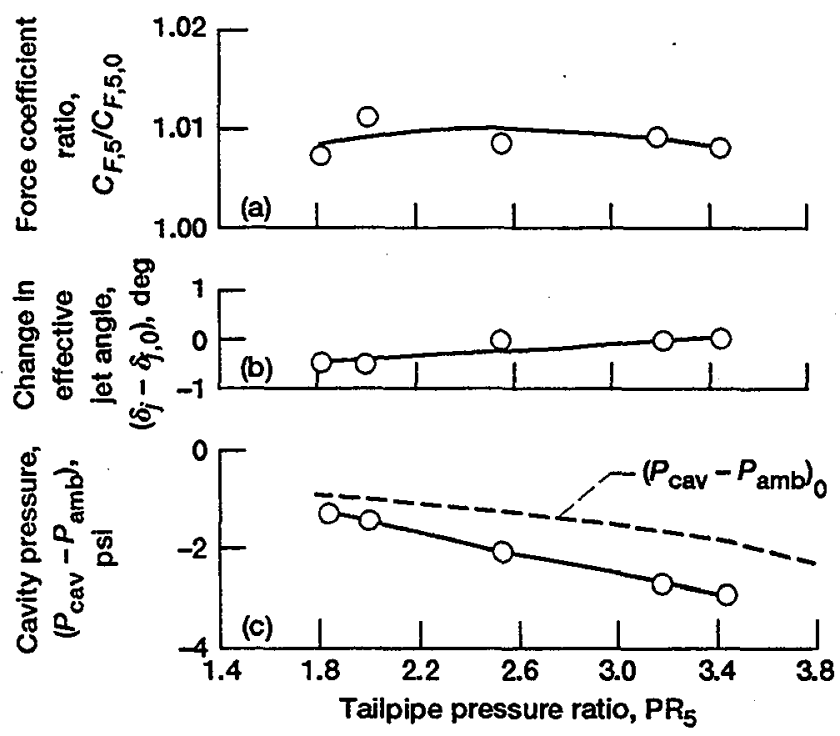

Figure C-4.-Performance with pumped air for nominal longvane angle of $30^{\circ}$. Pumped flow ratio, 1.5 percent; nominal throat area, $A_{\text {basic. }}$ 


$\begin{array}{crr} & \begin{array}{c}\boldsymbol{\delta}_{\boldsymbol{R} V \text {,nom, }} \\ \text { deg }\end{array} & \begin{array}{c}\boldsymbol{\delta}_{\boldsymbol{F} \text {,nom }} \\ \text { deg }\end{array} \\ \Delta & -18.9 & -2.2 \\ \triangleright & -12.4 & 5.5 \\ 0 & -9.5 & 9.5 \\ \square & -7.3 & 11.4 \\ \diamond & -4.7 & 14.4 \\ \triangle & -2.5 & 17.0 \\ \nabla & -0.1 & 19.2 \\ \nabla & 5.0 & 24.0\end{array}$
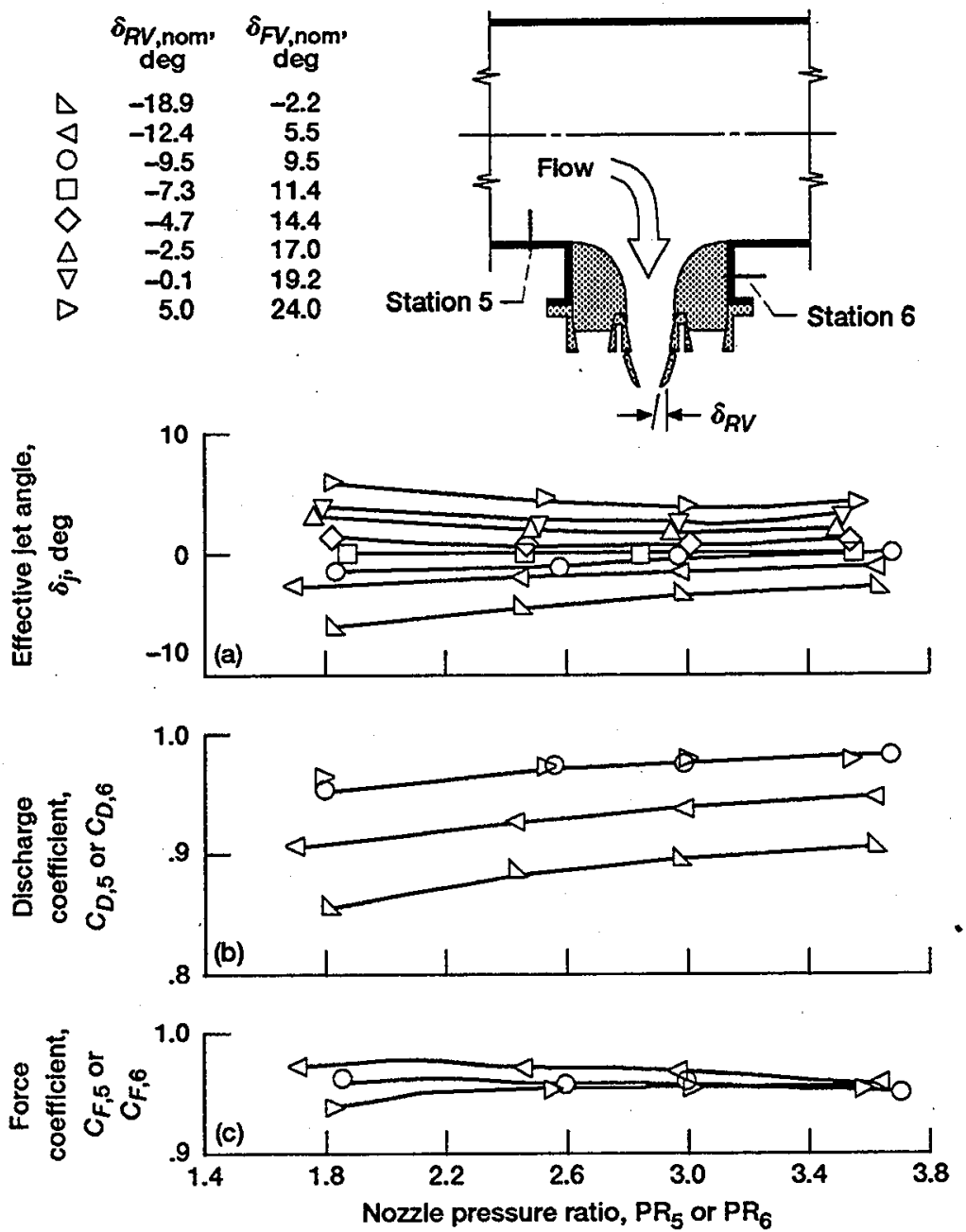

Figure D-1.-Measured performance of single vaneset with two long vanes. Nominal throat area, $A_{\text {basic }}$; geometric throat paralled to thrust axis when $\delta_{R V}=-7.5^{\circ}$. 

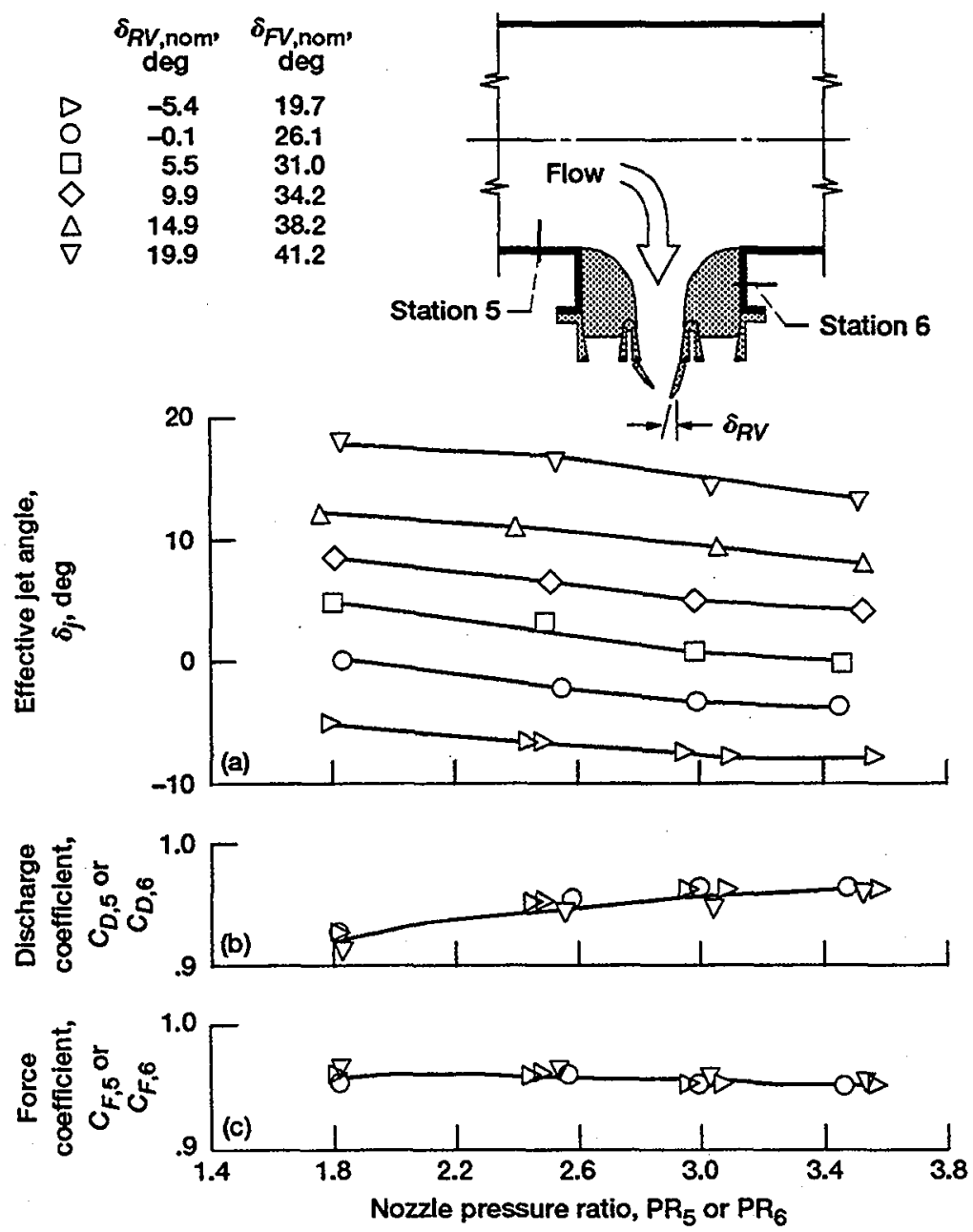

Figure D-2.-Measured performance of single vaneset with long rear vane and short front vane. Nominal throat area, $A_{\text {basici }}$ geometric throat parallel to thrust axis when $\delta_{R V}=-7.5^{\circ}$. 
Public reporting burden for this collection of information is estimated to average 1 hour per response, including the time for reviewing instructions, searching existing data sources, gathering and maintaining the data needed, and completing and reviewing the collection of information. Send comments regarding this burden estimate or any other aspect of this collection of information, including suggestions for reducing this burden, to Washington Headquarters Services, Directorate for information Operations and Reports, 1215 Jefferson Davis Highway, Suite 1204, Arlington, VA 22202-4302, and to the Office of Management and Budget, Paperwork Reduction Project (0704-0188), Washington, DC 20503.

\begin{tabular}{l|l|l} 
1. AGENCY USE ONLY (Leave blank) & 2. REPORT DATE & 3. REPORT TYPE AND DATES COVERED
\end{tabular}

4. TITLE AND SUBTITLE

June 1993

Technical Memorandum

Performance Characteristics of a Variable-Area Vane Nozzle for Vectoring an ASTOVL Exhaust Jet up to $45^{\circ}$

6. AUTHOR(S)

WU-505-68-32

Jack G. McArdle and Barbara S. Esker

5. FUNDING NUMBERS

7. PERFoRMING ORgANIZATION NAME(S) AND ADDRESS(ES)

8. PERFORMING ORGANIZATION

REPORT NUMBER

National Aeronautics and Space Administration

Lewis Research Center

Cleveland, Ohio 44135-3191

E-7768

9. SPONSORING/MONITORING AGENCY NAME(S) AND ADDRESS(ES)

10. SPONSORING/MONITORING AGENCY REPORT NUMBER

National Aeronautics and Space Administration

Washington, D.C. 20546-0001

NASA TM-106114

AIAA-93-2437

\section{SUPPLEMENTARY NOTES}

Prepared for the 29th AIAA Joint Propulsion Conference cosponsored by the AIAA, SAE, ASME, and ASEE, Monterey, California, June 28-30, 1993. Responsible person, Jack G. McArdle, (216) 433-3962.

12a. DISTRIBUTION/AVAILABILITY STATEMENT

12b. DISTRIBUTION CODE

Unclassified - Unlimited

Subject Category 07

\section{ABSTRACT (Maximum 200 words)}

Many conceptual designs for ASTOVL aircraft need exhaust nozzles that can vector the jet to provide forces and moments for controlling the aircraft's movement or attitude in flight near the ground. A type of nozzle that can both vector the jet and vary the jet flow area is called herein a vane nozzle. Basically, the nozzle consists of parallel, spacedapart flow passages formed by pairs of vanes (vanesets) that can be rotated on axes perpendicular to the flow. Two important features of this type of nozzle are the abilities to vector the jet rearward up to $45^{\circ}$ and to produce less harsh pressure and velocity footprints during vertical landing than does an equivalent single jet. A one-third-scale model of a generic vane nozzle was tested with unheated air at the NASA Lewis Research Center's Powered Lift Facility. The model had three parallel flow passages. Each passage was formed by a vaneset consisting of a long and a short vane. The longer vanes controlled the jet vector angle, and the shorter controlled the flow area. This report presents nozzle performance for three nominal flow areas (basic and \pm 21 percent of basic area), each at nominal jet vector angles from $-20^{\circ}$ (forward of vertical) to $+45^{\circ}$ (rearward of vertical). The tests were made with the nozzle mounted on a model tailpipe with a blind flange on the end to simulate a closed cruise nozzle, at tailpipe-to-ambient pressure ratios from 1.8 to 4.0 . Also included are jet wake data, single-vaneset vector performance for long/short and equal-length vane designs, and pumping capability. The pumping capability arises from the subambient pressure developed in the cavities between the vanesets, which could be used to aspirate flow from a source such as the engine compartment. Some of the performance characteristics are compared with characteristics of a single-jet nozzle previously reported.

14. SUBJECT TERMS

Short takeoff aircraft; Exhaust nozzles; Vanes; Propulsion system performance

15. NUMBER OF PAGES 34

16. PRICE CODE $\mathrm{A03}$
17. SECURITY CLASSIFICATION OF REPORT

Unclassified
18. SECURITY CLASSIFICATION OF THIS PAGE Unclassified
19. SECURITY CLASSIFICATION OF ABSTRACT

Unclassified 
National Aeronautics and Space Administration

Lewis Research Conter

Cleveland, Ohio 44135

Oritelal Dusinese

Pendiny for Priveto vas seco
FOURTH CLASS MALL

\section{ADDRESS CORRECTION REQUESTED}

